\title{
Transparency of Behavior-Based Pricing
}

\begin{abstract}
Collection and usage of consumers' purchase history data for behavior-based pricing (BBP) is a prevalent practice for firms and a worldwide concern for consumers. Extant research has examined BBP under the assumption that consumers observe whether firms practice BBP. However, consumers are often unaware of how firms collect and use their data. In addition, advances in information technology have reduced firms' cost of implementing BBP, which would seem to benefit them. We find that when consumers do not observe whether a firm practices BBP, the cost of implementing BBP has a non-monotone impact on firm profit, consumer surplus, and social welfare. Thus, reduction in the cost of implementing BBP can be detrimental to firms and beneficial to consumers. In particular, when the cost is low, a firm cannot help practicing BBP even though BBP is a dominated strategy when consumers observe it. When the cost is moderate, the firm does not use BBP; however, it must distort its first-period price downward to convince consumers of its choice, which causes the profit without BBP to be lower than the profit with BBP. A high cost of implementing BBP serves as a commitment device that the firm will forfeit BBP, thereby improving firm profit. We also find that a firm's ability to offer personalized enhanced service may decrease its profit. Moreover, consumer advocates call for regulations that mandate that firms disclose collection and usage of consumer data. However, it is unclear how such regulations might affect firms and consumers. By comparing regimes in which consumers observe and do not observe whether a firm practices BBP, we find that transparency of BBP increases firm profit but decreases consumer surplus and social welfare. Therefore, commanding firms to disclose collection and usage of consumer data could lead to unintended consequences.
\end{abstract}

Keywords: behavior-based pricing, privacy, transparency, signaling, game theory 
In the era of big data, firms use technologies such as Internet cookies, click-stream information, IP addresses, loyalty cards, and automatic data-gathering devices to collect consumers' data (Bread 2016). For example, the grocery store chain Kroger tracks the purchase history of its 55 million loyalty-card members (Monga 2014). Datalogix, a leading consumer data collection company, tracks purchases of more than 110 million U.S. households, pertaining to over $\$ 1$ trillion in spending on more than 1400 leading brands (Miller 2014). Consumers' data empowers firms to engage in behavior-based pricing $(\mathrm{BBP})$ - that is, to offer different prices to consumers with different purchase histories. "Sellers will use technology to extract the highest price they can from a particular shopper," Bill Gates commented, "This is an extension of pricing practices that are common today" (Woolley 1998).

Firms' practice of BBP is prevalent in a wide range of industries. For example, a major travel site offered different prices for the same airline ticket from New York City to Sydney under identical circumstances: $\$ 2,116$ for a consumer who used a browser indicating a robust history of purchasing flights and \$1,770 for a consumer without purchase histories (McGee 2013). Amazon listed a DVD for \$26.24 when consumers' computer identified them as regular Amazon consumers but a price of \$22.74 for unrecognized new consumers (Ramasastry 2005). Safeway and Kroger use loyalty card holders' purchase history data to send out personalized coupons (Clifford 2012, Landes 2012). Sam's Club introduced checkout apps that allow retailers to deliver customized prices to consumers (Wells 2017). According to Steve Burd, the CEO of Safeway, 'There's going to come a point where our shelf pricing is pretty irrelevant because we can be so personalized in what we offer people"(Choi 2013).

Despite the prevalence of BBP, consumers are often unaware of whether a particular firm collects and uses their information to price discriminate them. Two factors contribute to consumers' lack of awareness. First, they do not observe a particular firm's investment in data-collecting infrastructures and decision to practice BBP (Acquisti, Brandimarte, and Loewenstein 2015). Therefore, although consumers may know that firms collect and use consumer data, they cannot detect whether the particular firm they interact with collects and uses their data for BBP. Second, firms typically do not clearly communicate to consumers how they collect, use, and exploit consumers' data (Miller 2014). "Though some companies are open about their data practices, most prefer to keep consumers in the dark, choose control over sharing, and ask for forgiveness rather than permission" (Morey, Forbath, and Schoop 2015). Indeed, a Federal Trade Commission study found that $80 \%$ of randomly sampled websites that collect consumer information do not provide clear 
and conspicuous notice of their information collection or explicitly ask for consumers' consent (FindLaw 2018).

Although consumers cannot directly observe whether firms use their data for BBP, many express general concerns about data privacy. Industry surveys show that $91 \%$ of consumers agree or strongly agree that consumers have lost control of how companies collect and use their personal information (Rainie 2016), $73 \%$ believe that websites know too much about them, and $68 \%$ indicate that they would like regulations enacted to protect their privacy (Janrain 2018).

Firms' secret collection and usage of consumers' data for BBP have also generated considerable concerns from legislative authorities worldwide (e.g., Goldfarb and Tucker 2011). In 2014, Germany found Google's collection of individual user data without users' consent a violation of the Federal Telemedia Act and Federal Data Protection Act. Google was ordered to take necessary measures to guarantee that its users could decide on their own if, and to what extent, their data could be used (Esser 2014). In 2016, the European Union (EU) passed the General Data Protection Regulation (GDPR), which went into effect on May 25, 2018. The GDPR sets a higher bar for obtaining personal data than previous regulations. By default, any time a company collects personal data on an EU citizen, it needs to obtain explicit and informed consent from that person (Brandom 2018).

In the United States, personal data laws are not clearly defined or enforced by any independent governing body, and thus debate about the legality of BBP is ongoing. In 1996, a Manhattan consumer Denise Katzman sued Victoria's Secret for distributing different versions of catalogs with identical items but different prices. However, the New York Court dismissed the claim by noting that it was an accepted business practice to reward repeat consumers or to draw in new consumers with special savings (Miller 1996). Any form of price discrimination is legal in the United States, as long as the basis of discrimination is not race, religion, national origin, gender, or the like (Ramasastry 2005).

Although the practice of BBP is legal, consumer advocates call for regulations that should at least mandate that firms disclose the practice of BBP to consumers (Weiss and Mehrotra 2001, Miller 2014). The intension is that consumers should be aware of firms' collection and usage of their purchase history data for future price discrimination against them. With this information, consumers can choose whether to purchase from such firms and give away their data. For this purpose, in 2012, the Ensuring Shoppers Transparency in Online Pricing (E-STOP) Act ${ }^{1}$ proposed rules that require Internet merchants to disclose to consumers whether they use their personal information

${ }^{1}$ H.R. 6508, 112th Cong., 2nd sess. (September 21, 2012). 
for price discrimination ( $\mathrm{Li}$ and Jain 2016). The White House has issued several Big Data reports about firms' BBP practice since 2014. Nevertheless, it is inconclusive whether regulations should be introduced to require disclosure of BBP practice to consumers (InsidePrivacy 2015). Extant research offers little guidance for public policy makers in undertaking this important regulation, because it has mainly examined BBP under the assumption that consumers can directly observe whether firms practice BBP. Research has not investigated how firms make BBP and pricing decisions when consumers do not observe whether firms practice BBP. Therefore, it is unclear how transparency of BBP affects firms, consumers, and social welfare.

Moreover, rapid advances in information technology and data science have substantially reduced the cost of implementing BBP. For example, the data storage cost for a gigabyte of a hard drive has decreased $75 \%$ from $\$ 0.11$ in 2009 to \$0.028 in 2017 (Klein 2017, Li 2018). Web innovators, such as Facebook, Google, and Yahoo, offer scalable storage and compute architecture to manage firms' consumer data, dramatically reducing the cost of data storage and management (Savitz 2012). When consumers can observe whether firms practice BBP, research suggests that firms should forfeit BBP, which implies that the cost of implementing BBP is irrelevant. On the surface, it seems that even when consumers do not observe BBP, firms should weakly benefit from the reduced cost of BBP implementation. However, whether this intuition is true is subject to formal investigation.

The objective of this article is to fill these research gaps. Specifically, we address the following research questions: (1) When consumers do not observe whether a firm practices BBP, how does the firm decide whether to use BBP and set prices? (2) How does the cost of implementing BBP affect the firm's profit, consumer surplus, and social welfare? and (3) How does transparency of the firm's BBP practice affect firm profit, consumer surplus, and social welfare? Answers to these questions can guide firms in making BBP investment and pricing decisions when consumers cannot observe whether they invest in BBP. Our results also provide important guidance for public policy makers charged with regulating transparency of BBP to protect consumer privacy and welfare.

To address these questions, we consider a three-period game-theoretic model in which a monopolist firm first decides whether to incur a fixed cost $F$ to implement BBP in period 0. Then, the firm sells a repeatedly purchased product to consumers in periods 1 and 2 . We examine a benchmark model in which consumers observe whether the firm practices BBP (i.e., a perfect-information regime with transparency of $\mathrm{BBP}$ ) and a main model in which consumers do not observe whether the firm practices BBP (i.e., an imperfect-information regime without transparency of BBP). Under imperfect information, consumers form a belief about the firm's usage of BBP based on observed first-period price. In this regime, we examine the firm's BBP usage and pricing decisions and assess 
how the cost of implementing BBP affects firm profit, consumer surplus, and social welfare. Last, we compare the two regimes with and without transparency of BBP to evaluate the effects of BBP transparency on firm profit, consumer surplus, and social welfare.

Our analysis yields several important findings. First, research has established that when consumers observe whether firms practice BBP, BBP leads to lower profits. Therefore, firms do not invest in data collection for BBP in period 0. By contrast, we find that when consumers do not observe whether firms practice BBP, the firm may choose to invest in data collection for BBP in period 0. Specifically, the firm invests in BBP when the cost of implementing BBP is low. In this case, BBP enables the firm to improve second-period profit by price discriminating between previous and new consumers. However, because consumers do not observe the firm's investment in BBP, such investment in BBP does not affect their purchase decision or firm profit in the first period. Therefore, in contrast with the perfect-information benchmark, using BBP is beneficial: the firm guarantees a higher second-period profit through price discrimination without affecting its first-period profit.

Second, we find that when the cost of implementing BBP is in a moderate range, the firm does not invest in BBP but needs to distort its first-period price downward. Such price distortion renders the second-period practice of BBP unprofitable, thereby convincing consumers of its choice to abandon BBP. As a result, the firm's profit from not using BBP can end up lower than when the firm incurs a cost to use BBP. This result is in contrast with the common finding in the literature that firm profit is lower when firms practice BBP than when they do not practice BBP. We find that the firm's profit with $\mathrm{BBP}$ is higher than its profit without BBP. This price distortion is unnecessary when the cost of implementing BBP is high, because a high cost sends a credible signal to consumers that the firm will not make a profit from using BBP. Therefore, a high cost serves as a commitment device that the firm will not deviate by using BBP.

Third, when consumers do not observe whether a firm practices BBP, the cost of implementing BBP has a non-monotone impact on firm profit. That is, when the cost is low, the firm incurs the cost to implement BBP, and its profit decreases with the cost. When the cost is moderate or high, a lower cost of implementing BBP makes investment in BBP more profitable, leading consumers to question whether the firm invests in BBP. As such, the firm needs to distort its first-period price more to convince consumers that it does not invest in BBP and its profit declines accordingly. In addition, given that downward price distortion benefits consumers and enables more consumers who could not otherwise afford the product to consume it, consumer surplus and social welfare increase when the firm distorts its price downward. These results imply that as information and 
data technology advance, the decrease in the cost of implementing BBP can hurt firms and benefit consumers and society as a whole.

Fourth, comparison of the equilibrium outcomes with and without transparency of BBP shows that transparency increases firm profit but also decreases consumer surplus and social welfare. This is because transparency of BBP enables a firm to credibly commit to not practicing BBP without distorting its price downward. Therefore, regulations that mandate that firms disclose their collection and usage of consumers' data for BBP are actually beneficial to firms and detrimental to consumers and society. Thus, our research cautions public policy makers that regulations designed to protect consumer privacy and welfare can lead to unintended consequences.

Last, we extend the main model to examine the case when the firm has had previous transactions with customers and thus can offer them personalized enhanced service. We find that the firm's ability to offer such service reduces its profit when the cost of implementing BBP is high but not too high. The rationale is that the firm's ability to offer personalized enhanced service improves the profitability of BBP. As a result, when the cost of implementing BBP is high such that the firm chooses not to practice BBP, convincing consumers of its choice becomes increasingly costly. Therefore, the firm's ability to offer enhanced service decreases its profit. We also discuss how our main intuitions continue to hold in competitive settings as well as situations when consumers use anonymizing technologies to hide their identity.

\section{RELATED LITERATURE}

This article is closely related to the stream of research on BBP (Fudenberg and Villas-Boas 2006). A series of studies has established that when consumers observe whether firms invest in BBP, BBP reduces firm profits. Therefore, firms should not practice BBP even when practicing BBP is costless. This conclusion applies to both monopoly and duopoly settings. BBP reduces a monopolist's profit because of the ratchet effect: knowing that a firm uses BBP, consumers understand that it will use their first-period purchase decisions to price discriminate against them in the second period. Strategic consumers have incentives to postpone purchase to enjoy the low price for new consumers in the second period. Thus, the firm must reduce first-period prices to induce strategic consumers to buy in the first period. The firm's profit declines accordingly and is lower than when it does not invest in BBP and charges a single price (Villas-Boas 2004). Thus, although it is feasible for a monopolist to use BBP, it will never find it optimal to do so (Acquisti and Varian 2005). Fudenberg and Tirole (2000) use a two-period model to illustrate that BBP is also unprofitable for competing firms, though the mechanism is different from that in a monopoly. In particular, BBP leads 
competing firms to poach each other's customers. Competition in the second period becomes more intense and firms' total profits decline from the level without BBP. Villas-Boas (1999) draws the same conclusion by analyzing overlapping generations of consumers in an infinite-period game. Zhang (2011) further shows that when firms customize the horizontal attributes of products, profits become even lower than when firms only practice BBP. Research has also found some contexts in which firms can profit from BBP, such as when consumers have heterogeneous demand and preferences change over time (Shin and Sudhir 2010), asymmetric firms determine product quality (Jing 2017), consumers care about price fairness ( $\mathrm{Li}$ and Jain 2016), competing products are vertically differentiated (Rhee and Thomadsen 2017), or consumers are sufficiently averse to loss on match quality (Amaldoss and He 2018).

This article differs from the rich body of research on BBP in three important respects: First, prior studies assume that firms' practice of BBP is transparent and consumers can observe whether they implement BBP or not. By contrast, our research examines situations when consumers cannot observe whether firms practice BBP. Second, we compare situations when consumers observe and do not observe BBP to assess how transparency of BBP affects firms and consumers. Third, research commonly assumes that practicing BBP is costless. Therefore, the firm always collects consumer purchase history data and cannot commit to future prices (or equivalently, commit to ignoring consumers' purchase history data). Then, the firm will always use that information to price discriminate against the consumers in the second period. By contrast, our model endogenizes the firm's information collection decision in period 0 and allows for a cost for investment in data infrastructure and collection for BBP. The treatment of costly BBP is consistent with the notion that "firms are making massive investments into building information infrastructures that allow them to collect, store and analyze consumer data" (Acquisti and Varian 2005). Sadowski (2016) also notes that "Gathering [data] requires expertise in creating, extracting, refining and using it. This often goes hand-in-hand with increasingly invasive systems for probing, monitoring and tracking people." Furthermore, we show that the cost of implementing BBP has a non-monotone effect on firm profit, consumer surplus, and social welfare. These findings add new insights to the BBP literature and shed light on the public policy implications of regulations on consumer privacy and transparency of BBP.

This article considers situations in which consumers do not observe whether a firm practices BBP; thus, the firm signals its (unobserved) BBP decision to consumers through its (observed) price decision. This type of game differs from classic signaling games in that the firm's private type is its endogenous decision; we refer to this as the endogenous signaling game (In and Wright 2018). 
Endogenous signaling games are most often assessed in the context of quality signaling, in which the product quality is firms' private choice. Klein and Leffler (1981) investigate a model in which firms decide their product qualities which are not observed by consumers, and show how firms can use price to signal their quality. Wolinsky (1983) considers a similar signaling game but assumes that consumers have noisy information about the true quality of the products. Bester (1998) finds that imperfect information about the product quality can reduce competing firms' incentives for horizontal product differentiation. Endogenous signaling games have been used in other contexts as well. For example, Rao and Syam (2001) analyze two competing supermarkets each selling two goods. Each supermarket only advertises the price of one good, and consumers infer the price of the unadvertised good from the price of the advertised good. Li, Rocheteau, and Weill (2012) examine the liquidity of assets in trade, in which agents choose a portfolio of genuine and fraudulent assets for trade and the terms of trade. Other related research include Lester, Postlewaite, and Wright (2012), Rhodes (2014) and Gomis-Porqueras, Julien, and Wang (2017).

In many situations, researchers find that imperfect observability can trigger opportunistic behavior, which yields inefficient equilibrium outcomes. In a one manufacturer, two retailers setup, Hart and Tirole (1990), O'Brien and Shaffer (1992), and McAfee and Schwartz (1994) all discover that, when a retailer cannot observe the contract terms between the manufacturer and the rival retailer, the manufacturer has an incentive to opportunistically renegotiate another's contract to increase bilateral profit at the retailer's expense. As a result, downstream competition becomes too fierce, and the manufacturer cannot achieve the first-best outcome. Coughlan and Wernerfelt (1989) show that, under supply chain competition, when the structure of one supply chain is not observed by the rival chain, strategic decentralization never occurs as an equilibrium outcome, in contrast with the finding of McGuire and Staelin (1983). Janssen and Shelegia (2015) find that, when consumers are uninformed about the wholesale prices manufacturers charge to retailers, the equilibrium prices become inefficiently high, which worsens double marginalization and lowers manufacturers' profits. Ben-Porath, Dekel, and Lipman (2018) show that the unobservability of project choice can induce firm managers to choose riskier and less profitable projects. Roy, Gilbert, and Lai (2018) reveal that in a distribution channel, when the manufacturer cannot observe the retailer's inventory level, the retailer will opportunistically overstock, which backfires on its own profit. In this article, we examine the effect of unobservability in the context of BBP. While the literature on unobservability assumes that the firm is free to make its (unobserved) choices, we assume that the firm must incur a cost to practice BBP. The unobservability of the BBP decision also leads to the firm's opportunistic behavior: it cannot help opportunistically practicing BBP when the BBP 
implementation cost is low. Moreover, when the BBP implementation cost is moderate, the firm does not practice BBP; however, it must distort its price to convince consumers of its choice. Such distortion has not been covered in the literature.

This research is also related to studies on consumer privacy and transparency of firm decisions. For example, Rossi and Chintagunta (2016) find that posting fuel price signs (i.e., transparency of prices) decreases price levels without affecting price dispersions. Tucker (2014) empirically shows that when consumers have control over how their personally identifiable information to be used to personalize ads, they become nearly twice more likely to click on personalized ads. Our article supplements these studies by examining how transparency of firm's BBP practice affects prices, firm profit, consumer surplus, and social welfare.

\section{THE MODEL}

To assess how BBP transparency affects firms and consumers, we consider two regimes: with and without transparency of BBP. The first regime reflects situations when regulations require the firm to disclose its choice of BBP (i.e., $s \in\{\mathrm{BBP}, \emptyset\}$ ) to consumers. In this case, consumers have perfect information about whether the firm practices BBP. In the second regime, no regulations require the firm to disclose its BBP choice to consumers. Without the government's oversight, the firm cannot credibly disclose its BBP choice to consumers. Therefore, consumers have imperfect information about whether the firm practices BBP.

The model consists of three periods, $t=0,1,2$. A monopolist firm sells a repeated-purchased product in the market. The unit cost to produce the product is constant, and we normalize it to zero. To simplify analysis and exposition, we assume that both the firm and the consumers are risk neutral and do not discount the future.

\section{Information Collection and Behavior-Based Pricing}

Technology infrastructures such as customer relationship management systems and data storage and management allow the firm to collect consumer information, practice BBP, and price discriminate between consumers who bought and did not buy in a previous period. At $t=0$, the firm chooses whether or not to incur a cost $F$ to invest in these data-collecting technologies for BBP. If the firm invests in BBP, it collects consumer information that allows it to classify consumers as either "previous" or "new" consumers. Subsequently, the firm is able to price discriminate against consumers on the basis of their purchase histories. Alternatively, if the firm chooses not to invest in BBP (denoted by $\emptyset$ ), it cannot collect consumers' information or price discriminate against them. Let $s \in\{\mathrm{BBP}, \emptyset\}$ denote the firm's period-0 choice of whether or not to invest in BBP. 
For the moment, we assume that the firm can only use consumer information to price discriminate against consumers. Later, we extend the model by considering the case when the firm can also offer personalized enhanced service to previous consumers.

\section{Consumers}

Consider now the demand side. There is a continuum of consumers with total mass normalized to 1. Each consumer has unit demand for the product at $t=1$ and $t=2$. Consumer $i$ 's valuation for the product is constant over time and uniformly distributed over the unit interval (i.e., $v_{i} \sim \mathrm{U}[0,1]$ ).

We assume that all consumers are sophisticated: they understand how their purchase behavior will affect their future prices and take it into account when making their purchase decisions. In particular, consumers understand that when the firm uses BBP, buying early may not be the best strategy because doing so reveals higher preferences to the firm, which induces the firm to charge them a higher price in the future.

\section{Timing and Decisions}

The game unfolds in three periods. At $t=0$, the firm decides whether or not to invest in BBP (i.e., $s \in\{\mathrm{BBP}, \emptyset\}$ ). If the firm invests in $\mathrm{BBP}(s=\mathrm{BBP})$, it incurs the implementation cost $F$. At $t=1$, the firm has no specific information about individual consumers and thus offers a single price $p_{1}$ to all consumers whether or not it practices BBP. After sales commence, the firm cannot practice $\mathrm{BBP}$ if it failed to make an investment earlier. Actions at $t=2$ depend on the firm's choice of $s$. If $s=\mathrm{BBP}$, the firm offers two prices to the two identified groups: a price $p_{2}^{r}$ to all previous consumers who purchased the product at $t=1$ and a price $p_{2}^{n}$ to all new consumers who did not purchase the product. If $s=\emptyset$, the firm again offers a single price $p_{2}$ to all consumers. Figure 1 summarizes the sequence of events.

\section{Benchmark Regime: With Transparency of BBP}

When a firm is required to give consumers clear and conspicuous privacy notices whenever it collects and uses consumer data for BBP, the firm's BBP decision becomes public information in the market. Knowing that the firm does not collect their information, consumers need no longer fear being price discriminated against by the firm in the future. We first analyze the transparency regime, in which consumers perfectly observe the firm's choice $s \in\{\mathrm{BBP}, \emptyset\}$ after it is made. We solve the model using backward induction and state results in Lemma 1 and Table 1. 


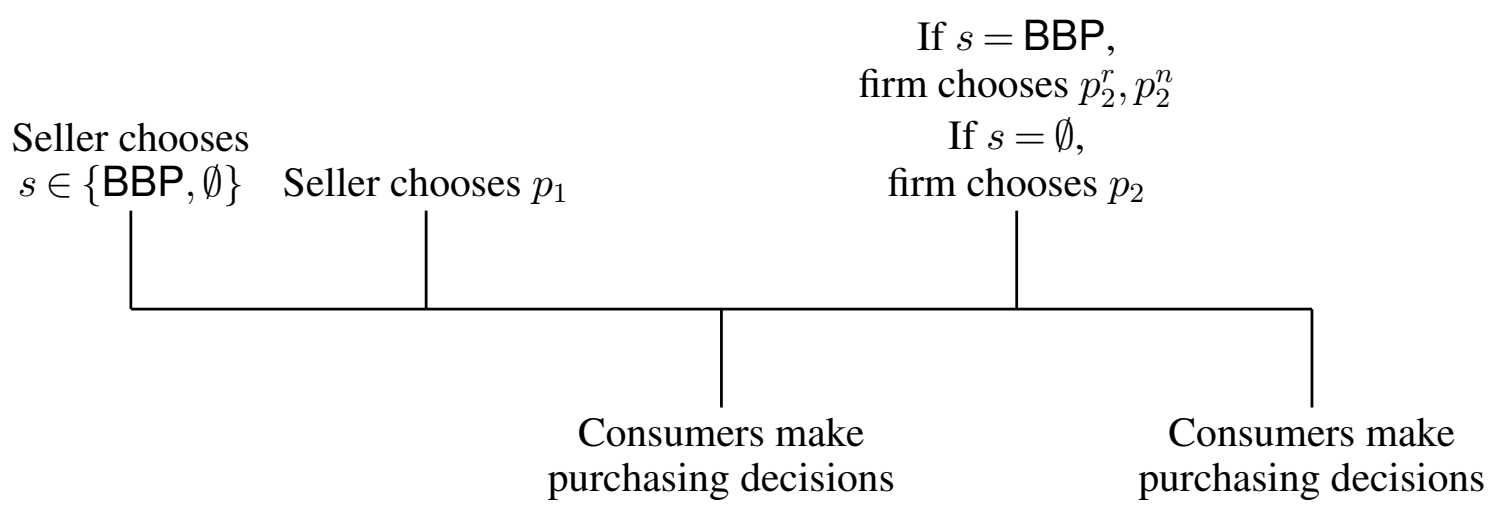

Figure 1 Sequence of events

LEMMA 1. With transparency of BBP (i.e., under perfect information), given any BBP decision $s$, it is optimal for the firm not to practice BBP (i.e., the optimal s is $\emptyset$ ).

Table 1 Optimal decisions and maximal profit under perfect information

\begin{tabular}{|c|c|c|c|c|}
\hline & $p_{1}$ & $\pi_{1}$ & $\pi$ & $\pi$ \\
\hline $\begin{array}{l}s=\emptyset \\
s=\mathrm{BBP}\end{array}$ & $\begin{array}{c}\frac{1}{2} \\
\frac{3}{10} \quad p_{2}^{r}=\frac{3}{2}, p_{2}^{n}=\frac{3}{10}\end{array}$ & $\begin{array}{l}\overline{4} \\
\frac{3}{25}\end{array}$ & $\frac{3}{13}$ & $\frac{\frac{1}{2}}{20}-F$ \\
\hline
\end{tabular}

The results in Table 1 indicate that, under perfect information, the firm is always worse off practicing BBP (with at least $10 \%$ loss of profit). The intuition is as follows: with BBP, when a consumer buys at $t=1$, the firm knows that this consumer has high valuation and thus charges him or her a higher price at $t=2$. This price discrimination effect works to the benefit of the firm. However, fearing that the firm will price discriminate against them, some consumers defer their purchases until $t=2$. Anticipating this reluctance to purchase, the firm must offer a lower initial price to induce period-1 purchases. This negative ratchet effect yields a profit loss for the firm. In line with previous BBP research (e.g., Villas-Boas 2004, Acquisti and Varian 2005), in our perfectinformation setup, the ratchet effect dominates the price discrimination effect, and it is in the best interest of the firm not to practice BBP.

As Table 1 shows, if $s=\mathrm{BBP}$, the firm's profit decreases with $F$. Alternatively, if $s=\emptyset$, the firm's profit does not change with $F$. Because the firm always chooses $s=\emptyset, F$ has no effect on the firm's profit. However, as we show subsequently, when consumers do not observe the firm's choice $s, F$ becomes critical to the firm's choice of BBP, prices, and profit, even when the firm does not practice BBP. 


\section{MAIN REGIME: WITHOUT TRANSPARENCY OF BBP}

In this section, we consider the main regime when consumers do not observe whether the firm invests in BBP. We discuss the information structure and the solution concept and then solve the equilibrium.

\section{Information Structure and Solution Concept.}

Because consumers do not observe the firm's choice of $s$, the model falls into a game of imperfect information. We solve the game using the solution concept of perfect Bayesian equilibrium (PBE), under which consumers hold a belief about what the firm has chosen and act optimally given their belief.

Note that our model differs from classic signaling games because within our model, it is the firm, not nature, that makes the choice $s \in\{\mathrm{BBP}, \emptyset\}$. This class of game is also known as the endogenous signaling game (In and Wright 2018), in which a sender (the firm) "signals" its private choice to receivers (consumers). As PBE does not impose any restrictions on beliefs off the equilibrium paths, the endogenous signaling games normally suffer from a plethora of equilibria. To focus on the most reasonable equilibria, we resort to reordering invariance (RI) as our refinement criterion. RI was initially proposed in In and Wright (2018) and has been widely used in the literature (e.g., Lester, Postlewaite, and Wright 2012, Li, Rocheteau, and Weill 2012, Rhodes 2014).

As described previously in the game, the firm first makes its unobserved choice $s \in\{\mathrm{BBP}, \emptyset\}$ and then makes the observed choice $p_{1}$. According to RI, a reasonable perfect Bayesian equilibrium should also be an equilibrium when we reverse these two decisions. For the current game, a reasonable equilibrium should also hold when the firm first makes the observed choice $p_{1}$ and then makes the unobserved choice $s \in\{\mathrm{BBP}, \emptyset\}$. RI has an intuitive appeal. According to In and Wright (2018), if the firm chooses the (observed) period-1 price $p_{1}$ before making the (unobserved) BBP decision $s$, then a subgame starts from the choice of $p_{1}$. We could then apply subgame perfection to discover consumers' belief about $s$, which should be optimal given $p_{1}$. Now, suppose instead that the $\mathrm{BBP}$ decision $s$ is made first, there is no proper subgame (except for the whole game), and PBE itself does not impose any restrictions on beliefs off the equilibrium path. As such, there will be a large number of equilibria arising from various specifications of the consumers' out-of-equilibrium beliefs. Nevertheless, as the firm makes its BBP decision $s$ and price decision $p_{1}$ without gaining any information in between, the order in which it makes the two decisions should not matter. Intuitively, even if the BBP decision is made before the price decision, the firm should already have in mind the price it is going to set. Following this logic, a rational firm should make the same 
choices for $s$ and $p_{1}$ no matter which decision it makes first. For consumers, they are aware that the firm's BBP decision $s$ should be optimally chosen given the price $p_{1}$. As a result, they can take the observed price $p_{1}$ as if it was chosen first.

In compliance with RI, in our analysis, we consider the reordered game in which the firm first chooses its first-period price $p_{1}$ and then decides whether to practice BBP. ${ }^{2}$ Because the firm's choice of $s$ is private, we must distinguish the firm's actual choice, $s$, from consumers' conjecture about that choice, which we illustrate as follows: after observing $p_{1}$, consumers form their belief of $s=\mathrm{BBP}$, which is denoted as $\Lambda\left(p_{1}\right) \in[0,1]$. That is, if $\Lambda\left(p_{1}\right)=1$, consumers believe that the firm always practices BBP; if $\Lambda\left(p_{1}\right)=0$, consumers believe that the firm does not practice BBP. If $\Lambda\left(p_{1}\right)$ is in between, consumers believe that the firm randomizes its choice between BBP and $\emptyset$.

\section{Analysis}

We now solve for the equilibrium without transparency of BBP (i.e., under imperfect information). With RI-refinement, it suffices to consider the reordered game in which the firm first makes the observed decision on $p_{1}$ and then makes the unobserved decision on $s$. The solution entails first solving for the subgame following the choice of $p_{1}$. We then use the results to derive the firm's optimal choice of $p_{1}$. To break ties, we assume that when the firm is indifferent about whether or not to practice BBP, it does not practice BBP. We relegate the detailed analysis to the Appendix and present the equilibrium outcomes in Proposition 1 and Table 2.

PROPOSITION 1. Without transparency of BBP (i.e., under imperfect information), the firm practices $B B P$ when $F \leq \frac{7-2 \sqrt{10}}{45} \approx 0.015$.

Table 2 Equilibrium Strategies under Imperfect Information

\begin{tabular}{|c|c|c|cc|ccc|}
\hline & cost & $s$ & $p_{1}$ & $p_{2}$ & $\pi_{1}$ & $\pi_{2}$ & $\pi$ \\
\hline \hline$F<\frac{7-2 \sqrt{10}}{45}$ & low & BBP & $\frac{3}{10}$ & $p_{2}^{r}=\frac{3}{5}, p_{2}^{n}=\frac{3}{10}$ & $\frac{3}{25}$ & $\frac{33}{100}$ & $\frac{9}{20}-F$ \\
$\frac{7-2 \sqrt{10}}{45} \leq F \leq \frac{1}{16}$ & medium & $\emptyset$ & $2 \sqrt{F}$ & $\frac{1}{2}$ & $2 \sqrt{F}-4 F$ & $\frac{1}{4}$ & $2 \sqrt{F}-4 F+\frac{1}{4}$ \\
$\frac{1}{16}<F$ & high & $\emptyset$ & $\frac{1}{2}$ & $\frac{1}{2}$ & $\frac{1}{4}$ & $\frac{1}{4}$ & $\frac{1}{2}$ \\
\hline
\end{tabular}

Prior research assumes away the cost of implementing BBP (Fudenberg and Tirole 2000, Esteves 2009), because when consumers observe whether a firm practices BBP, the firm forfeits BBP in

\footnotetext{
${ }^{2}$ In the reordered game, the firm still makes its BBP decision before the period-1 sale commences. Therefore, the firm's BBP
} decision does not hinge on consumers' period-1 purchase behavior. 
period 0, and this cost has no impact on firm profit. By contrast, Proposition 1 reveals that when consumers do not observe whether a firm practices BBP, the cost of implementing BBP plays a critical role in the firm's BBP and pricing decisions. We also show that the impact of $F$ on firm profit, consumer surplus, and social welfare is non-monotone. Next, we discuss the results and insights when $F$ is at different levels.

$F$ is low: endogenous choice of BBP. In contrast with the prediction that firms do not practice BBP under the perfect-information assumption, Proposition 1 shows that when $F$ is low and consumers cannot observe the firm's choice of BBP, BBP can become the firm's equilibrium choice. This result is relevant because new technology has significantly reduced the cost of data storage and management for implementing BBP. Thus, this result suggests that as the cost of implementing BBP continues to decline over time, we expect to witness growing practice of BBP.

To illustrate the intuition, we consider the special case that implementing BBP is costless (i.e., $F=0$ ). Recall that the perfect-information equilibrium is that the firm does not practice BBP (i.e., $s=\emptyset$ ), charges $p_{1}=p_{2}=\frac{1}{2}$, and gains a total profit of $\pi=\frac{1}{2}$. This equilibrium no longer holds when consumers cannot observe the firm's practice of BBP. Assume for contradiction that the perfect-information equilibrium still holds when consumers cannot observe the firm's choice $s$. Consider the following deviance: the firm deviates by choosing $\tilde{s}=$ BBP in period 0 but still charges $\tilde{p}_{1}=\frac{1}{2}$ in period 1 . This guarantees that consumers do not observe any deviance in period 1 (they only observe $\tilde{p}_{1}=p_{1}$ ). Therefore, consumers' beliefs are not affected: they hold the (incorrect) belief that the firm does not practice BBP. As such, all consumers with valuation $v_{i} \geq \frac{1}{2}$ will purchase the product, and the firm's period-1 profit is $\tilde{\pi}_{1}=\frac{1}{4}$. In period 2 , the firm can do better by price discriminating against consumers: it charges previous consumers a higher price $\tilde{p}_{2}^{r}=\frac{1}{2}$ and new consumers a lower price $\tilde{p}_{2}^{n}=\frac{1}{4}$. As a result, the firm's second-period profit is $\tilde{\pi}_{2}=\frac{5}{16}$, and its total profit is $\tilde{\pi}=\tilde{\pi}_{1}+\tilde{\pi}_{2}=\frac{9}{16}>\pi=\frac{1}{2}$. Thus, the firm is better off deviating, and the assumed equilibrium does not exist.

Therefore, when consumers cannot observe the firm's choice $s$, the firm has an incentive to opportunistically practice BBP. By practicing BBP, the firm can price discriminate against consumers in period 2. Meanwhile, because consumers do not observe the deviance, the firm's deviance does not affect its period-1 profit. Thus, the ratchet effect in the perfect-information case does not apply. Therefore, choosing $s=$ BBP is unanimously beneficial: the firm guarantees a higher second-period profit through the price discrimination effect without affecting its period-1 profit. 
Following the same logic, given any price $p_{1}$, when the cost of implementing BBP is low (i.e., $F<\frac{7-2 \sqrt{10}}{45}$ ), the value of price discrimination is above the cost of BBP. Therefore, the firm chooses to practice BBP to take advantage of the price discrimination effect. As all consumers are sophisticated, in equilibrium, they correctly account for the firm's opportunistic incentive, form their beliefs and make purchase decisions accordingly.

However, as Table 1 shows, practicing BBP turns out to be unprofitable compared with the firm's first-best solution under perfect information. Despite reduced profits with BBP, the firm has no means to escape from practicing BBP under imperfect information.

$F$ is medium: downward price distortion. As long as the cost of implementing BBP is not low (i.e., $F \geq \frac{7-2 \sqrt{10}}{45}$ ), the cost counters the benefit of price discrimination. As a result, the firm chooses not to invest in BBP. Interestingly, as Table 2 and Figure 2 show, when the cost of implementing BBP is medium (i.e., $\frac{7-2 \sqrt{10}}{45} \leq F<\frac{1}{16}$ ), $p_{1}<\frac{1}{2}$; that is, there is a downward distortion in the firm's period-1 price. To understand the firm's first-period price distortion, we examine the relationship between the second-period value of price discrimination and the first-period price $p_{1}$.

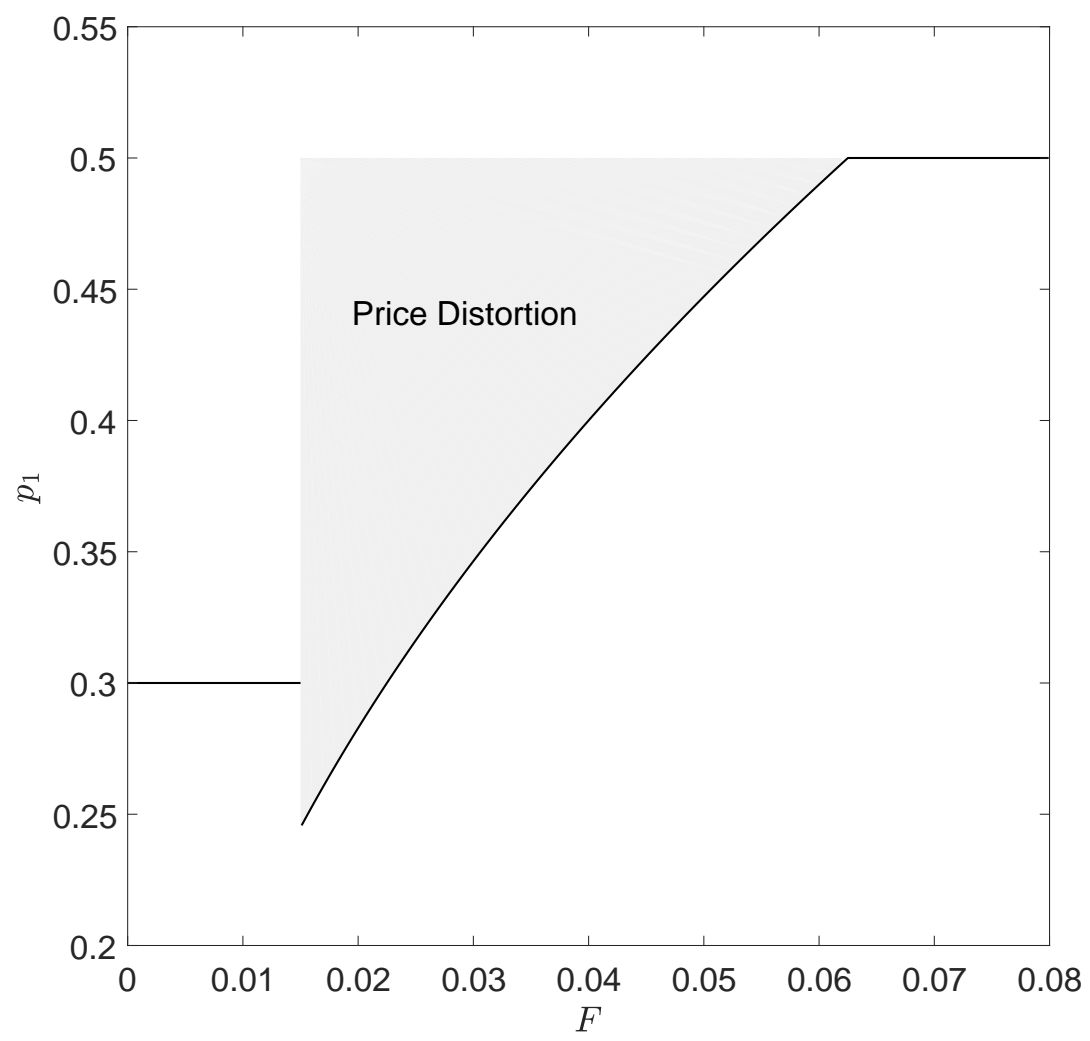

Figure 2 The firm's first-period price 


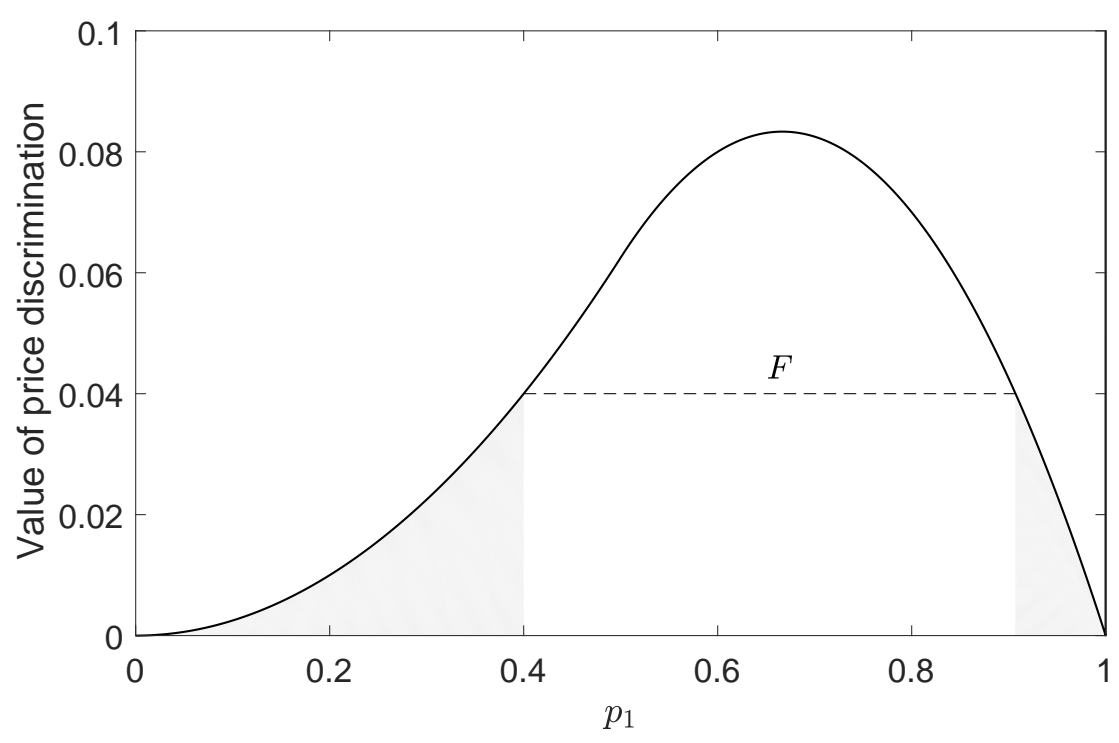

Figure 3 the value of price discrimiation

In Figure 3, we plot the value of the price discrimination effect as a function of $p_{1}$, where

The value of price discrimination $=\pi_{2}^{\mathrm{BBP}}-\pi_{2}^{\emptyset}= \begin{cases}\frac{p_{1}^{2}}{4} & \text { if } p_{1}<\frac{1}{2} \\ p_{1}-\frac{3 p_{1}^{2}}{4}-\frac{1}{4} & \text { otherwise }\end{cases}$

In other words, the value of price discrimination is equal to the difference in second-period profits with and without BBP. As Figure 3 shows, the value of price discrimination is minimized at either low or high values of $p_{1}$ and is maximized when $p_{1}$ is moderate. The intuition for the result is as follows: in the extreme case when $p_{1}$ is 0 (1), all (no) consumers make an initial purchase in period 1 , and the purchase history data contains virtually no information. In either case, the firm cannot price discriminate against consumers. At moderate $p_{1}$, however, there are both large segments of consumers who purchase and who do not purchase in period 1, and the purchase history data becomes more informative. As such, the firm can improve its profit substantially by price discriminating against the consumers.

The value of price discrimination is, however, not symmetric around $p_{1}=\frac{1}{2}$, and it peaks at $p_{1}=$ $\frac{2}{3}$ (see Figure 3 ). This result is not obvious because the purchase history data is most informative at $p_{1}=\frac{1}{2}$ in the "entropy" sense (Shannon and Weaver 1949). The intuition is as follows: to the firm, the information about high-valuation consumers is more useful than information about lowvaluation consumers. In the extreme case, identifying a consumer of valuation $v_{i}=0$ is not useful because that consumer will never be served in the market. When $p_{1}$ is high (but not too high), 
the firm gains more precise information about high valuation consumers and thus benefits more from that information. Thus, while purchase history data is most informative at $p_{1}=\frac{1}{2}$, it is most valuable at $p_{1}=\frac{2}{3}$.

In line with this logic, to avoid the BBP equilibrium, the firm must be willing to distort its firstperiod price to reduce the profitability of price discrimination (to make it lower than the cost of implementing BBP). As Figure 3 shows the firm can either distort its first-period price downward or distort it upward to make the price discrimination less valuable. Given the asymmetry in the value of price discrimination discussed previously, the firm prefers downward distortion to upward distortion, because the associated distortion is less severe when the firm distorts $p_{1}$ downward (for a detailed discussion, see the Appendix). In equilibrium, the firm distorts its price downward to $p_{1}=2 \sqrt{F}$ to commit to a no-BBP equilibrium. Given that all consumers with valuation $v \in$ $[2 \sqrt{F}, 1]$ will make an initial purchase, the firm is indifferent about whether or not to practice BBP. Therefore, the price distortion is necessary to signal the firm's endogenous choice $(s=\emptyset)$ to consumers.

$F$ is high: commitment device. Finally, when the cost of implementing BBP is high (i.e., $F \geq \frac{1}{16}$ ), $\mathrm{BBP}$ becomes unprofitable, which enables the firm to commit to not price discriminating against consumers even without the need to distort its price. Therefore, a high cost serves as a commitment device for the firm. In equilibrium, the firm prices efficiently at $p_{1}=\frac{1}{2}$ and achieves the first-best outcome. The resulting equilibrium is equivalent to the perfect-information benchmark.

In summary, when consumers do not observe whether a firm practices $\mathrm{BBP}$, the cost of implementing $\mathrm{BBP}(F)$ is critical to the firm's BBP and pricing decisions. This is the case even when the firm chooses not to practice BBP. The results that the firm chooses BBP when $F$ is low, distorts its first-period price downward when $F$ is moderate, and credibly forfeits BBP when $F$ is high are new insights to the BBP literature.

\section{Firm's Profit}

When the cost of implementing BBP is low (i.e., $F<\frac{7-2 \sqrt{10}}{45}$ ), the firm always practices BBP, and its total profit is given by

$$
\pi=-F+(1-\hat{v}) \cdot p_{1}+\min \left\{1-\hat{v}, 1-p_{2}^{r}\right\} \cdot p_{2}^{r}+\left(\hat{v}-p_{2}^{n}\right) p_{2}^{n},
$$

where $\hat{v}$ is the indifferent consumer in period 1. Otherwise, the firm does not practice $\mathrm{BBP}$, and its total profit is given by 


$$
\pi=\left(1-p_{1}\right) \cdot p_{1}+\left(1-p_{2}\right) \cdot p_{2}
$$

The following proposition summarizes the results.

PROPOSITION 2. Without transparency of BBP (i.e., under imperfect information), the firm's equilibrium profit $\pi$ is as follows:

(i) When $F<\frac{7-2 \sqrt{10}}{45}$, $\pi$ decreases in $F$; when $\frac{7-2 \sqrt{10}}{45} \leq F \leq \frac{1}{16}$, $\pi$ increases in $F$.

(ii) $\pi$ is minimized when $F=\frac{7-2 \sqrt{10}}{45}$ and maximized when $F \geq \frac{1}{16}$.

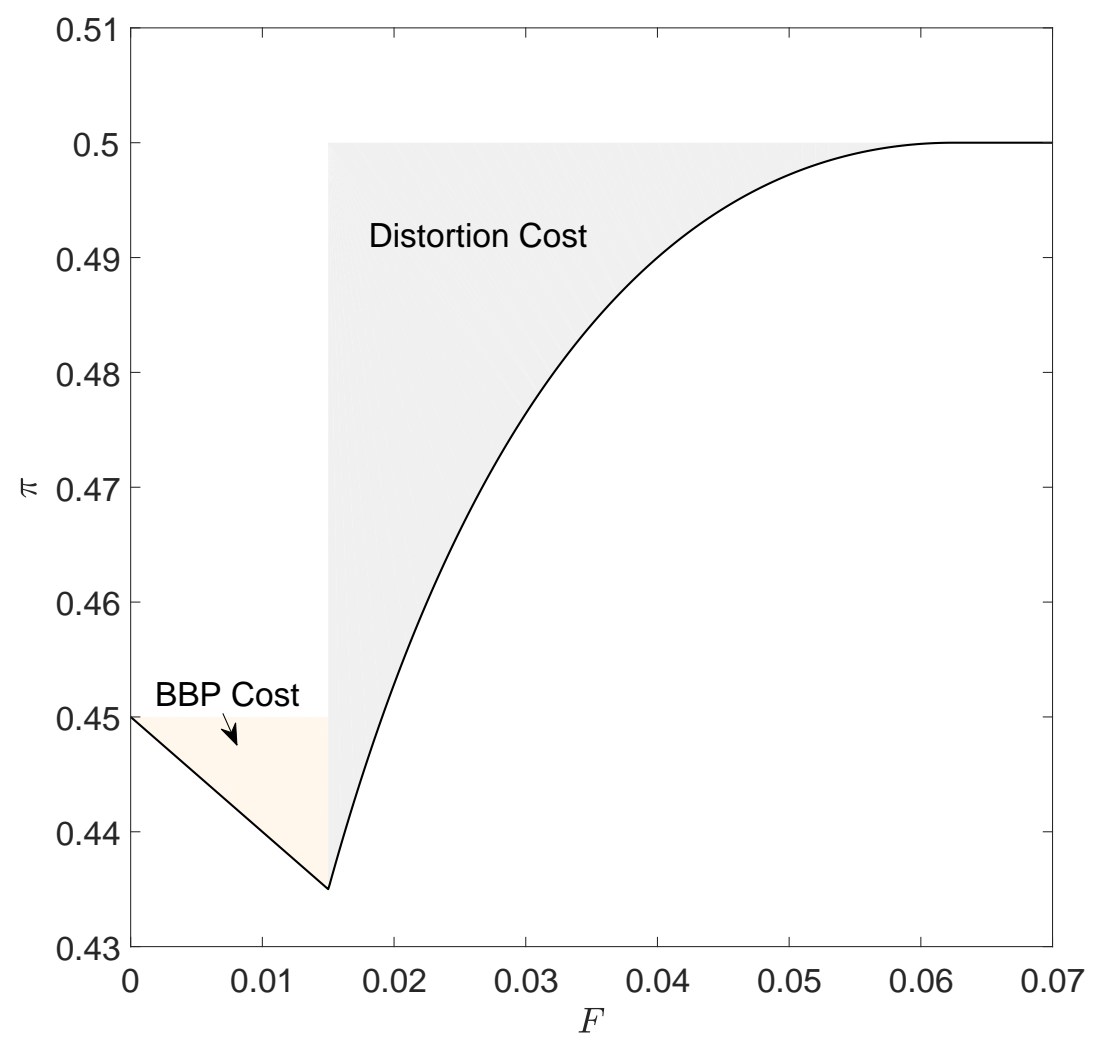

\section{Figure 4 The firm's equilibrium profit}

Figure 4 illustrates the firm's equilibrium profit. Part (i) of Proposition 2 and Figure 4 suggest that the firm's profit is not monotone in $F$; that is, it decreases in $F$ when $F$ is low and increases in $F$ otherwise. This result suggests that advances in information technologies do not always benefit firms. They can also reduce firm profit when $F$ is moderate or high.

The rationale is as follows: when $F$ is low, the firm cannot help opportunistically practicing BBP, as Proposition 1 suggests. As such, a higher $F$ implies that the firm incurs higher costs when 
implementing BBP, which affects the firm's profit negatively. This effect is represented by the first term on the right-hand side of Equation (1). By contrast, when $F$ is moderate, the firm prefers the no-BBP equilibrium to the BBP equilibrium. However, to convince consumers that it does not practice BBP, the firm must distort its first-period price downward $\left(p_{1} \leq \frac{1}{2}\right)$, which makes the price discrimination less profitable. As $F$ increases, practicing BBP becomes less profitable for the firm and the firm could signal its choice $(s=\emptyset)$ to consumers more easily (i.e., with lesser distortion). This effect is represented by the first term on the right-hand side of Equation (2), which increases in $F$. As such, the firm benefits from an increase in $F$.

In line with this logic, when $F$ is neither low nor high, both the BBP equilibrium and the no-BBP equilibrium are costly to achieve: to practice BBP, the firm must incur a considerable implementation cost; not to practice BBP, the firm must distort its price severely to signal its choice to consumers. Part (ii) of Proposition 2 indicates that the firm's profit reaches its minimum of $\pi \approx 0.435$ when $F=\frac{7-2 \sqrt{10}}{45}$, a $13 \%$ profit loss compared with the perfect-information benchmark. When $F$ is high enough (i.e., $F \geq \frac{1}{16}$ ), $\mathrm{BBP}$ is too costly to implement, and the firm could signal its choice $s=\emptyset$ without distorting its first-period price. The firm's profit is maximized at $\pi=\frac{1}{2}$, which is equivalent to that in the perfect-information benchmark.

Note also that as a result of the price distortion, when $\frac{7-2 \sqrt{10}}{45} \leq F \leq \frac{3-\sqrt{5}}{40}$ (at which the firm does not practice BBP), the firm's profit is lower than when the firm incurs a small cost (i.e., $F$ is close to zero) to practice BBP. We can illustrate this point with a numerical example. If $F=0.016$, the firm chooses not to invest in BBP. To convince consumers of this decision, it distorts first-period price to $p_{1}=0.253$ and makes a profit of $\pi=0.439$. If $F=0.005$, the firm invests in BBP, and its profit with BBP is $\pi=0.445>0.439$. Comparing the two profits, we show that the firm's profit with BBP is higher than the profit without BBP. This result is in contrast with the literature that shows that a firm's profit is lower when it practices BBP than when it does not practice BBP (i.e., Acquisti and Varian 2005, Fudenberg and Tirole 2000). Next, we examine consumer surplus and social welfare without transparency of BBP.

\section{Consumer Surplus}

Proposition 3 summarizes the result.

PROPOSITION 3. Without transparency of BBP (i.e., under imperfect information), consumer surplus, $C S$, is given by 


$$
C S= \begin{cases}\frac{13}{40} & \text { if } F<\frac{7-2 \sqrt{10}}{45} \\ \frac{5}{8}-2 \sqrt{F}+2 F & \text { if } \frac{7-2 \sqrt{10}}{45} \leq F \leq \frac{1}{16} \\ \frac{1}{4} & \text { otherwise. }\end{cases}
$$

where

(i) $C S$ is constant in $F$ when $F<\frac{7-2 \sqrt{10}}{45}$ or $F>\frac{1}{16}$ and decreases in $F$ when $\frac{7-2 \sqrt{10}}{45} \leq F \leq \frac{1}{16}$.

(ii) There is a discontinuous increase in $C S$ at $F=\frac{7-2 \sqrt{10}}{45}$.

(iii) $C S$ is maximized when $F=\frac{7-2 \sqrt{10}}{45}$ and is minimized when $F \geq \frac{1}{16}$.

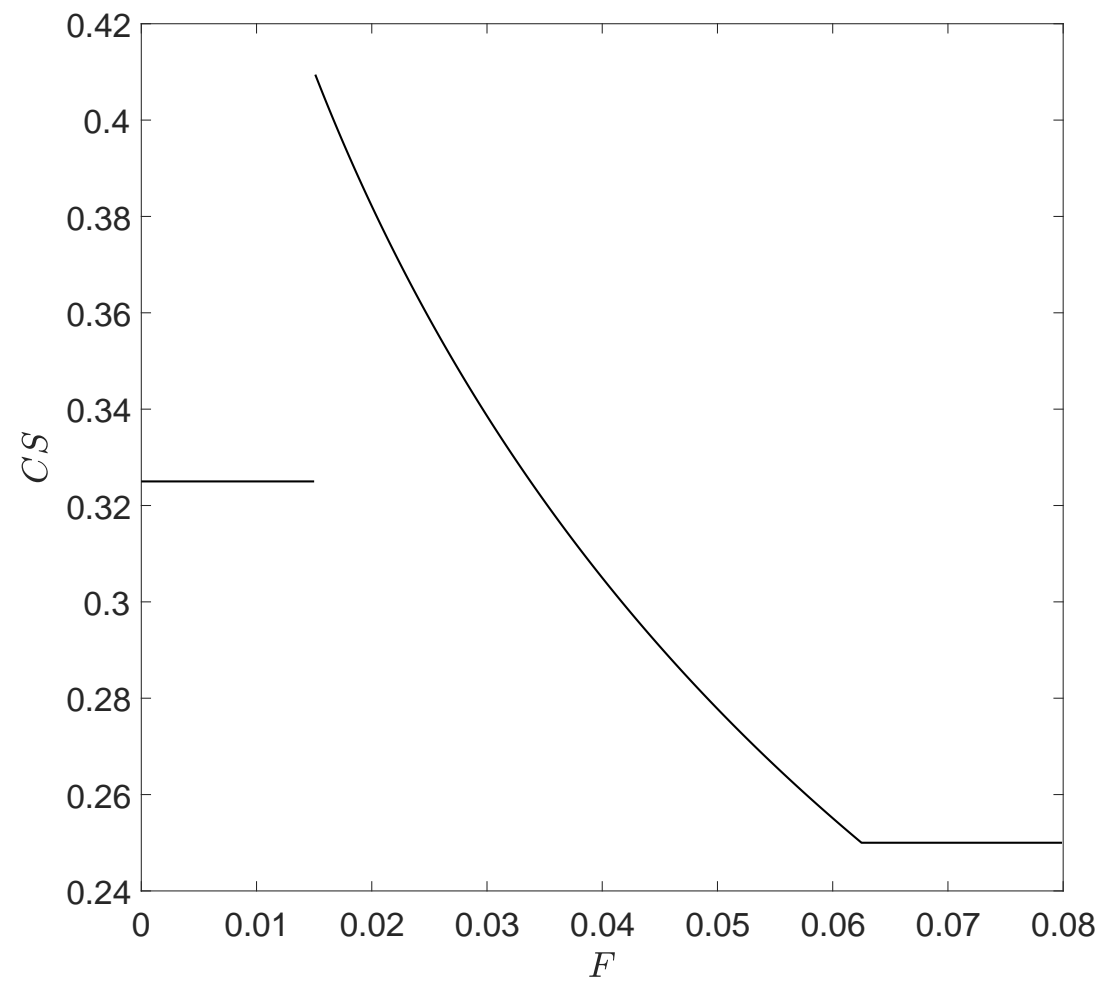

Figure 5 Equilibrium consumer surplus

As Part (i) shows, consumer surplus is constant in $F$ when $F$ is either low or high. When $F$ is low, the firm always charges the optimal BBP prices, whereas when $F$ is high, the firm always charges the optimal no-BBP prices (i.e., there is no price distortion). Therefore, prices and consumer surplus are constant in $F$. By contrast, when $F$ is moderate, the firm prefers the no-BBP 
equilibrium but distorts its first-period price downward to signal its choice. The downward distortion in $p_{1}$ benefits consumers in two ways: First, a lower price increases the utility of consumers who purchase the product. Second, a lower price enables consumers who could not afford the product at a higher price to purchase it. As $F$ increases, there is lesser price distortion (see Figure 2), and consumer surplus decreases.

Part (ii) of Proposition 3 suggests that there is a discontinuous increase in $C S$ at $F=\frac{7-2 \sqrt{10}}{45}$. This discontinuity showcases the switch from the BBP equilibrium to the no-BBP equilibrium (with price distortion) at $F=\frac{7-2 \sqrt{10}}{45}$. Consumers benefit from the discontinuous decrease in the first-period price.

Part (iii) of Proposition 3 suggests that, compared with the firm's profit, which is maximized at high levels of BBP implementation costs, consumer surplus reaches its maximum at a moderate BBP implementation cost $\left(F=\frac{7-2 \sqrt{10}}{45}\right)$. At this cost, the firm decreases its first-period price significantly as a signal of its choice (i.e., $s=\emptyset$ ), and consumers benefit from such a low price. At $F=\frac{7-2 \sqrt{10}}{45}$, consumer surplus reaches 0.410 , a $64.0 \%$ improvement over the perfect-information benchmark. When $F \geq \frac{1}{16}$, the prices are too high in both periods, and consumer surplus suffers.

\section{Social Welfare}

Finally, consider the effect of $F$ on social welfare. Social welfare is the total value of firm profits and consumer surplus, whereas the cost of implementing BBP is a deadweight loss. Proposition 4 summarizes the result.

PROPOSITION 4. Without transparency of BBP (i.e., under imperfect information), social welfare, $S W$, is given by

$$
S W= \begin{cases}\frac{31}{40}-F & \text { if } F<\frac{7-2 \sqrt{10}}{45} \\ \frac{7}{8}-2 F & \text { if } \frac{7-2 \sqrt{10}}{45} \leq F \leq \frac{1}{16} \\ \frac{3}{4} & \text { otherwise. }\end{cases}
$$

where

(i) $S W$ decreases in $F$ when $F<\frac{7-2 \sqrt{10}}{45}$ or $\frac{7-2 \sqrt{10}}{45} \leq F<\frac{1}{16}$.

(ii) There is a discontinuous increase in $S W$ at $F=\frac{7-2 \sqrt{10}}{45}$.

(iii) $S W$ is maximized when $F=\frac{7-2 \sqrt{10}}{45}$ and is minimized when $F \geq \frac{1}{16}$. 


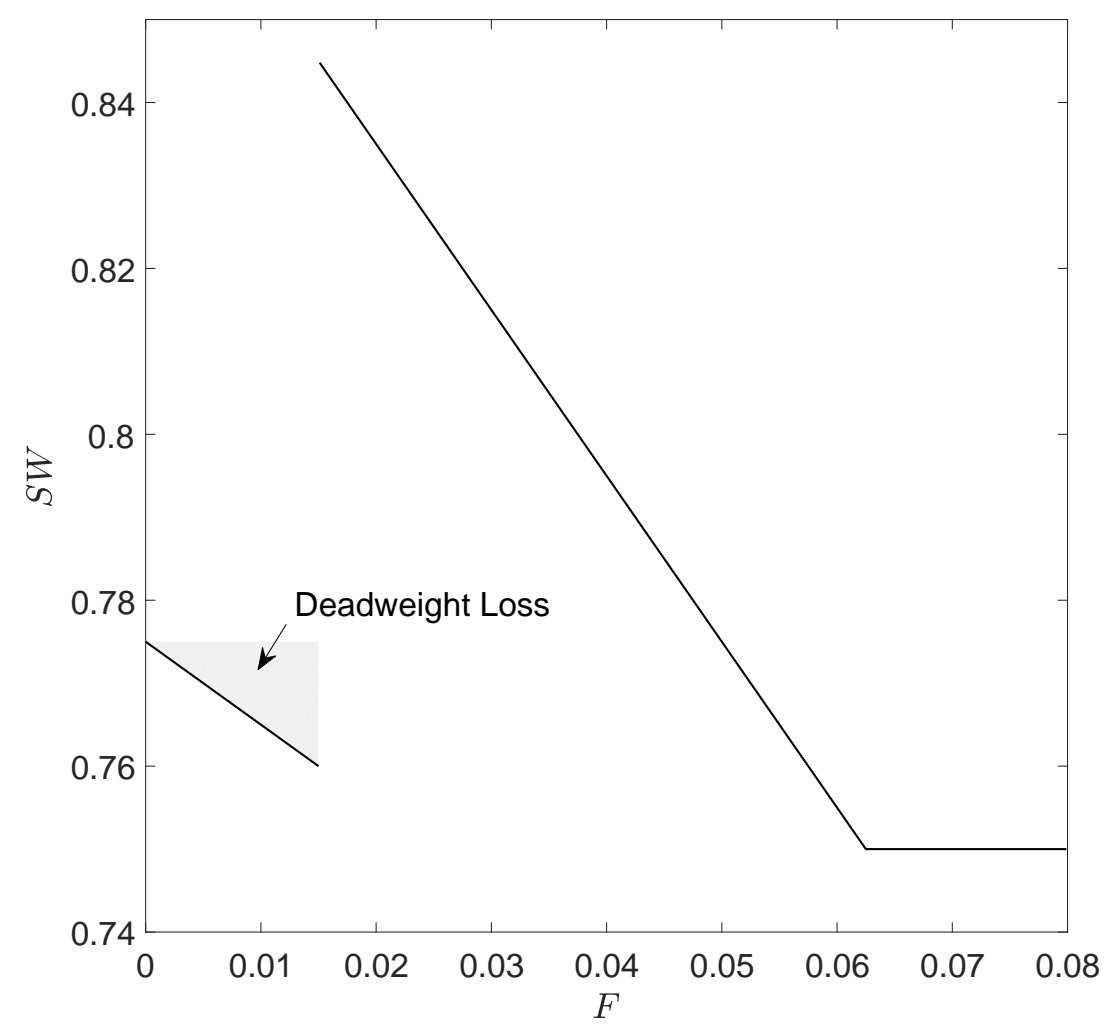

Figure 6 Equilibrium social welfare

Part (i) indicates that social welfare decreases in $F$ when $F$ is either low (i.e., $F<\frac{7-2 \sqrt{10}}{45}$ ) or moderate (i.e., $\frac{7-2 \sqrt{10}}{45} \leq F<\frac{1}{16}$ ), but for very different reasons. When $F \leq \frac{7-2 \sqrt{10}}{45}$, the firm practices BBP; social welfare decreases in $F$ because a higher $F$ exacerbates the deadweight loss in implementing BBP and makes the firm worse off (see Figure 6). When $\frac{7-2 \sqrt{10}}{45}<F<\frac{1}{16}$, the firm does not practice BBP but distorts its first-period price downward to signal its choice. While this price distortion hurts the firm, it benefits consumers because the first-period price is lower, which enables some consumers who otherwise could not afford the product to purchase it. The expansion in demand increases social welfare. Overall, social welfare gains from this price distortion. As $F$ grows, there is less price distortion, and $p_{1}$ increases, to the detriment of social welfare.

Part (ii) of Proposition 4 suggests that there is a discontinuous increase in $S W$ at $F=\frac{7-2 \sqrt{10}}{45}$. Again, this discontinuity showcases the switch from the BBP equilibrium to the no-BBP equilibrium at $F=\frac{7-2 \sqrt{10}}{45}$. This regime switch not only saves the BBP implementation cost but also leads to a discontinuous decrease in $p_{1}$, to the benefit of social welfare.

Consistent with Proposition 3, part (iii) of Proposition 4 shows that social welfare is maximized at $F=\frac{7-2 \sqrt{10}}{45}$. At this cost, social welfare enjoys a $12.7 \%$ improvement over the perfectinformation benchmark. When $F \geq \frac{1}{16}$, prices are too high in both periods, and social welfare 
suffers. $^{3}$

\section{Effects of Transparency of BBP}

A direct comparison between regimes with and without transparency of BBP reveals the overall effects of BBP transparency on firms, consumers, and social welfare.

PROPOSITION 5. Transparency of BBP improves the firm's profit but decreases consumer surplus and social welfare.

In view of this proposition, data transparency regulation enables a firm to commit not to practice BBP without having to distort its price. As a result, the firm benefits from the regulation and achieves its first-best outcome. However, data transparency regulation always works to the detriment of consumer surplus. When $F$ is low, consumer surplus is hurt because the first-period price is high when the firm forfeits price discrimination. When $F$ is medium or high, consumer surplus is (weakly) hurt because the firm no longer distorts its price, resulting in a higher first-period price and fewer consumers who can afford the product. For the same reason, although data transparency regulation helps the firm save the cost of implementing BBP, it reduces social welfare. Therefore, from the standpoint of a consumer advocate or social planner, a BBP transparency regulation can be inefficient and must be applied with caution. ${ }^{4}$

\section{PERSONALIZED ENHANCED SERVICE}

A firm can go further than price discrimination when it bases marketing activity on consumers' past purchasing behavior. In this section, we extend the base model by considering the case in which the firm could offer personalized enhanced service to previous buyers when it practices BBP. As Acquisti and Varian (2005) suggest, "such an enhanced service is based on information about the consumer's preferences. A consumer might frequent the same barber because that barber knows the consumer's preferences in haircuts. The barber, in turn, might charge a premium for his services because the consumer would have to incur costs in explaining to another barber exactly how his hair should be cut." In a similar vein, Pazgal and Soberman (2008) assume that, by practicing

\footnotetext{
${ }^{3}$ If a third party collects the fee $F$ for BBP implementation, our results still hold qualitatively. Specifically, when $F<\frac{7-2 \sqrt{10}}{45}$, the firm always practices BBP, and social welfare is given by $S W=\frac{31}{40}$. When $F \geq \frac{7-2 \sqrt{10}}{45}$, the firm does not practice BBP, and social welfare is the same as denoted in Proposition 4. Social welfare is still maximized when $F=\frac{7-2 \sqrt{10}}{45}$. In the case when the third party endogenously sets the BBP fee $F$, our analysis suggests that the third party optimally sets the fee at $F=\frac{7-2 \sqrt{10}}{45}-\varepsilon$ for some small $\varepsilon>0$. Under such a fee, the firm's profit is minimized.

${ }^{4}$ Proposition 5 continues to hold when a third party collects the cost of implementing BBP.
} 
BBP, a firm can collect information from its consumers related to needs that are not addressed by the first-period offer and add a benefit to its second-period offer. With advances in information technologies, personalized enhanced services are becoming increasingly common, as firms can offer automated personalized enhanced services by taking consumer information directly from their databases. Note that personalized enhanced service can only be offered when there is a prior transaction between the consumer and the firm; otherwise, the firm has no means to assess the preferences or needs of an individual consumer.

Under perfect information, the firm cannot be worse off when it has the ability to offer consumers personalized enhanced service. If the firm practices BBP, it can attain higher profits in period 2 from offering personalized enhanced service to the previous consumers. If the firm does not practice BBP, it cannot offer personalized enhanced service and its profit will not be affected. In either case, being able to offer personalized enhanced service does not hurt the firm. However, as we show subsequently, this is not the case under imperfect information.

Formally, let $\Delta \geq 0$ denote the benefit of the personalized enhanced service that the firm offers to previous consumers (see Pazgal and Soberman 2008 for a similar assumption). The cost of offering such service is normalized to 0 . The base model is thus a special case in which $\Delta=0$. We focus on the interesting case when $\Delta$ is small enough so that the firm still prefers the no-BBP equilibrium under perfect information. We maintain the timing of the base model and continue to let $F$ represent the cost of implementing BBP. We relegate the detailed analysis to the Appendix and present the equilibrium results in Proposition 6 and Table 3.

PROPOSITION 6. Suppose that the firm is able to offer personalized enhanced service to previous consumers. Without transparency of BBP (i.e., under imperfect information), in equilibrium, the firm practices $B B P$ when $F \leq F_{1}$.

As Proposition 6 indicates, consistent with the base model, in equilibrium the firm practices BBP when $F$ is low and does not practice BBP otherwise. In addition, $\frac{\partial F_{1}}{\partial \Delta}>0$; that is, personalized enhanced service leads to a wider range of situations for the firm to practice BBP. This is because the firm's ability to offer personalized enhanced service makes consumers' purchase history data more valuable. Here, consumers' purchase history data not only helps the firm price discriminate between previous and new consumers but also allows it to offer personalized enhanced service to previous consumers. As such, the firm finds BBP more profitable, and it is more willing to practice BBP at a moderate BBP implementation cost. 
Table 3 Equilibrium Strategies

\begin{tabular}{|c|c|cc|}
\hline & $s$ & $p_{1}$ & $p_{2}$ \\
\hline \hline$F<F_{1}$ & BBP & $\frac{3-2 \Delta}{10}$ & $p_{2}^{r}=\frac{3(1+\Delta)}{5}, p_{2}^{n}=\frac{3-2 \Delta}{10}$ \\
$F_{1} \leq F \leq \frac{1}{16}$ & $\emptyset$ & $\sqrt{4 F-2 \Delta-\Delta^{2}}$ & $\frac{1}{2}$ \\
$\frac{1+6 \Delta+5 \Delta^{2}}{16} \leq F \leq \frac{1+8 \Delta}{16}$ & $\emptyset$ & $\frac{2(1-\Delta)-\sqrt{(1+2 \Delta)^{2}-12 F}}{3}$ & $\frac{1}{2}$ \\
$\frac{1+8 \Delta}{16}<F$ & $\emptyset$ & $\frac{1}{2}$ & $\frac{1}{2}$ \\
\hline \multicolumn{2}{|c}{$F_{1}=\frac{1}{45}\left(7+24 \Delta+12 \Delta^{2}-\sqrt{5} \sqrt{8+6 \Delta+3 \Delta^{2}}\right)$}
\end{tabular}

Next, we examine whether the firm benefits from its ability to offer personalized enhanced service. Specifically, we analyze the effect of $\Delta$ on the firm's profit and present the results in Proposition 7.

PROPOSITION 7. The firm may be worse off if it can offer personalized enhanced service to consumers.

As Figure 7 shows, $\Delta=0$ corresponds to the case when the firm is unable to offer personalized enhanced service (or equivalently, consumers do not value personalized enhanced service at all). In terms of profit, the ability to offer personalized enhanced service positively affects the firm's profit at low levels of $F$ but reduces profit beyond a critical value of $F$. Why is the firm worse off with the ability to offer personalized enhanced service at high levels of $F$ ?

Recall that the firm practices BBP when $F$ is low and does not practice BBP when $F$ is high. First, consider the case of low $F$. The firm unanimously benefits from its ability to offer personalized enhanced service. This is because, in equilibrium, the firm will practice BBP, and being able to offer personalized enhanced service allows the firm to charge higher prices to previous consumers, which raises the firm's second-period profit. Second, consider the case of high $F$. The result is less obvious. As discussed previously, when $F$ is high, the firm prefers the no-BBP equilibrium to the BBP equilibrium; however, to convince consumers that it does not practice BBP, the firm must distort its first-period price downward, making BBP less profitable. When the firm has the ability to offer personalized enhanced service, BBP becomes more profitable, and convincing consumers that it forfeits BBP becomes increasingly difficult. As a result, the firm must distort the first-period price more to signal its choice of forfeiting BBP, which affects its profit negatively. Mathematically, $\frac{\partial \pi}{\partial \Delta}=\frac{\partial \pi}{\partial p_{1}} \cdot \frac{\partial p_{1}}{\partial \Delta} \leq 0$ when $F \geq F_{1}$.

\section{DISCUSSION}




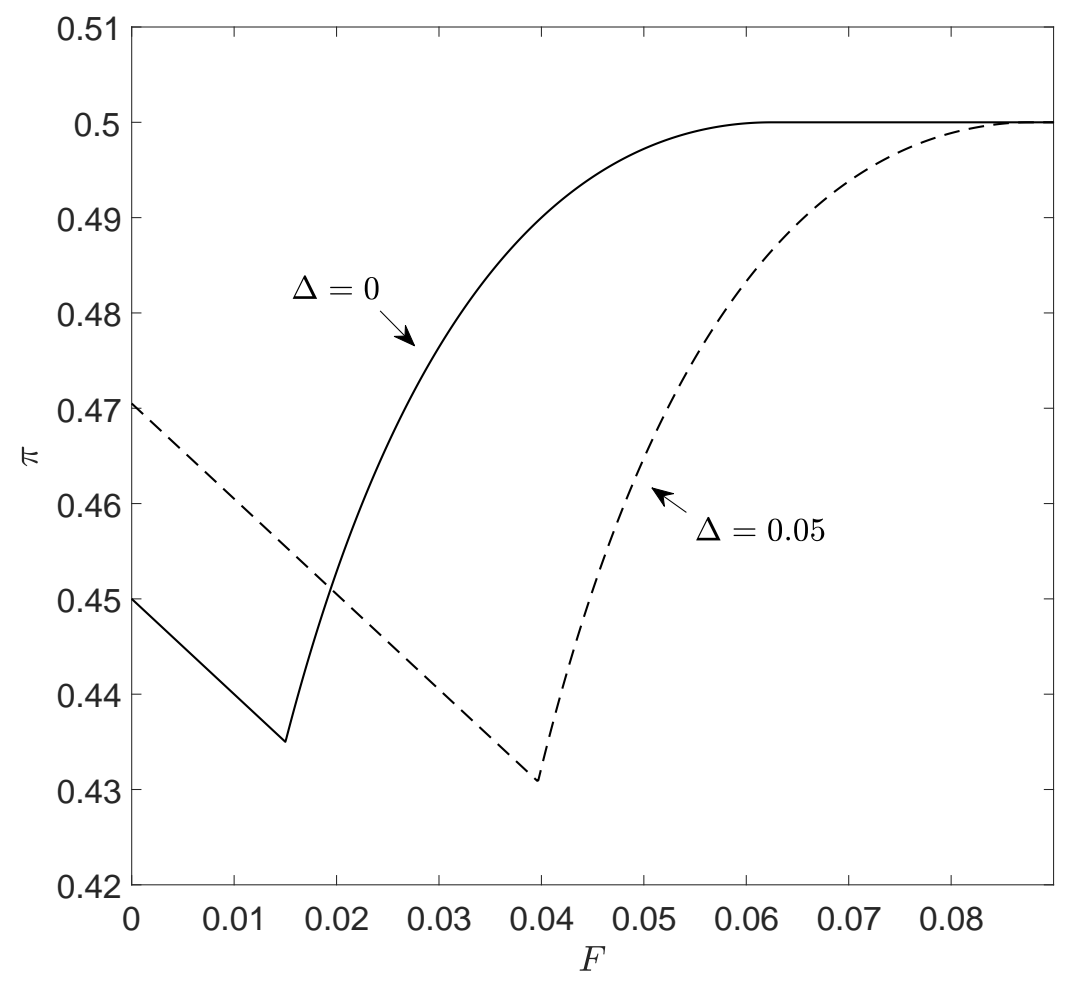

Figure 7 The effect of personalized enhanced services on the firm's profit

\section{Market Competition}

Our model considers a monopolist firm. Would the main results hold under market competition? In compliance with the literature, we consider a duopoly setting with two firms, $A$ and $B$, each selling a product to consumers in each of two periods, $t=1,2$. In period 0 , the firms decide whether to incur a cost $F$ to invest in data collection and storage for BBP (i.e., $s_{A}, s_{B} \in\{\emptyset, \mathrm{BBP}\}$ ). A firm's BBP decision is not observed by the rival firm or the consumers. In period 1, the firms simultaneously choose their observed first-period prices $p_{A 1}$ and $p_{B 1}$, and consumers make their initial purchase decisions. In period 2, contingent on their BBP decisions, the firms choose their second-period prices. That is, if firm $j \in\{A, B\}$ practices BBP, it offers two prices, $p_{j 2}^{r}$ and $p_{j 2}^{n}$, to previous and new consumers, respectively. Otherwise, it offers a single price $p_{j 2}$ to all consumers.

The duopoly setup differs from the main model in two ways. First, a firm signals its BBP decision not only to consumers but also to the rival firm. Firm $B$ 's second-period price depends critically on its belief about firm A's BBP decision. Second, under RI-refinement, there is no proper subgame in the reordered game in which the firms first choose their first-period prices and then make their BBP decisions. This is because firm $B$ makes its BBP decision $s_{B}$ without observing firm $A$ 's firstperiod price $p_{A 1}$. As such, subgame perfection does not pin down the out-of-equilibrium beliefs in 
the reordered game. These two substantially complicate the model, and we are not able to formally solve the duopoly model.

Despite this issue, our main insights should still hold in the duopoly setup: when the BBP implementation cost is zero or low, the firms cannot help opportunistically practicing BBP. To see this, assume for contradiction that, in equilibrium, neither firm practices BBP and both charge $p_{A 1}^{*}$ and $p_{B 1}^{*}$ in period 1. Consider the following deviance: firm $A$ secretly practices BBP but still charges

$p_{A 1}^{*}$. Because the deviance is not observed, the rival's and the consumers' beliefs about $s_{A}$ should not change, and firm $A$ 's first-period profit will not be affected. However, in period 2, firm $A$ enjoys an information advantage over its rival and makes a higher profit. Therefore, competition itself does not eliminate the opportunistic behavior of the firms. In line with this logic, when the cost of implementing BBP is high (but not too high), an equilibrium in which the firms do not practice BBP or distort their prices does not exist. Following the intuition from the base model, the firms may prefer not to practice BBP and distort their first-period prices to convince consumers of their choices. This reduces the value of consumers' purchase data, making BBP less profitable to practice.

\section{Consumer anonymity}

Our main model assumes that consumers do not use anonymizing technologies to block data collection and avoid being recognized by firms. Conitzer, Taylor, and Wagman (2012) show that consumers' ability to adopt anonymizing technologies affects the firm's selling strategy. Here, we discuss how our results could continue to hold if we allow consumers to hide their identity. When consumers observe whether a firm practices BBP, given that a firm never practices BBP, there is no need for consumers to anonymize. When consumers do not observe whether the firm practices BBP, the problem is more complicated. If the cost of anonymity is negligible, all consumers anonymize, and the firm achieves its first-best solution (it does not practice BBP or distort its first-period price). If the cost of anonymity is prohibitive, no consumers anonymize, and the equilibrium results in our main model apply. Now consider the case of a moderate cost of anonymity. When the cost of implementing BBP $(F)$ is low, a pure-strategy equilibrium in which the firm forfeits BBP does not exist. The intuition is as follows: assume for contradiction that such an equilibrium exists. Then, all consumers will be charged the same second-period price, and no first-period consumers will pay to anonymize. Given that the BBP implementation cost is low, the firm is better off practicing BBP to take advantage of the consumers' purchase history data, which contradicts the assumption. Thus, our main result that the firm cannot help practicing BBP when the BBP implementation cost 
is low still holds. In line with this logic, when the cost of implementing BBP is high (but not too high), the firm cannot achieve its first-best solution either. To avoid the BBP outcome, the firm can again distort its first-period price to reduce the value of the price discrimination effect. As such, the firm commits to a no-BBP equilibrium, and no consumers anonymize.

\section{CONCLUSION}

As technology advances, firms can increasingly collect and use consumers' purchase history data for BBP. Firms often practice BBP without explicitly communicating such practices to consumers. Therefore, consumers are often unaware of firms' exploitation of their purchase history data for BBP. The widespread but unobserved practice of BBP has drawn growing public attention and debate about whether regulations should require firms to disclose their BBP practice to consumers. Extant research on BBP commonly assumes that consumers can directly observe whether firms practice BBP (i.e., they assume perfect information). In this article, we investigate a firm's decision to implement BBP when consumers do not directly observe this decision (i.e., with imperfect information). Furthermore, we compare the market equilibria in the perfect-information regime and the imperfect-information regime to evaluate the implications of BBP transparency on firms and consumers. Our results provide several insights and implications.

When consumers do not observe whether a firm practices $B B P$, how does the firm make BBP and pricing decisions? Our analysis shows that when the cost of implementing BBP is low, the firm cannot help practicing BBP. This occurs because, when consumers cannot observe the firm's choice, the firm has an incentive to opportunistically practice BBP, thereby benefiting from the price discrimination effect without affecting consumers' first-period purchase behavior. When the cost of implementing BBP is moderate, the firm does not practice BBP; however, it must distort its first-period price downward to convince consumers of its choice. When the cost of implementing BBP is high, the firm does not practice BBP or distort its price, as the benefit of BBP is offset by the high cost, which convinces consumers that the firm does not practice BBP. Therefore, when consumers do not observe the practice of BBP, a firm should make BBP and pricing decisions differently from situations when consumers observe BBP, and these decisions should depend on the cost of implementing BBP.

How does the cost of implementing BBP affect the firm's profit, consumer surplus, and social welfare? We find that the cost of implementing BBP does not exert a monotone impact on the firm's profit. The firm's profit decreases in the implementation cost but only up to a point, after which it increases with the implementation cost. The cost of implementing BBP affects consumer surplus 
and social welfare in the reverse pattern of its impact on firm profit. Therefore, the declining cost of data storage and management for BBP could hurt firms but benefit consumers and society as a whole.

How does transparency of a firm's BBP practice affect firm profit, consumer surplus, and social welfare? Our comparison of the cases when consumers observe and do not observe BBP suggests that transparency of BBP improves firm profit at the cost of consumer surplus and social welfare. This is because mandatory disclosure of BBP serves as a commitment device that enables a firm to credibly commit to forfeiting BBP. As a result, the firm does not need to distort prices to costly signal to consumers about this decision. Therefore, transparency of BBP leads to higher prices, which benefit the firm but hurt consumers and society. This result implies that regulations that mandate that firms disclose the practice of BBP, designed to protect consumer privacy and welfare, could lead to unintended consequences.

How does a firm's ability to offer personalized enhanced service to consumers affect its profit? Our analysis shows that the ability to offer personalized enhanced service to consumers can either benefit or hurt the firm. When the BBP implementation cost is low, the firm practices BBP and gains from offering personalized enhanced service. However, when the BBP implementation cost is high, the firm's ability to offer personalized enhanced service reduces its profit. This is because, with this ability, it is increasingly costly for the firm to convince consumers that it does not practice BBP.

Future research could extend our study in several ways. First, the current model considers a monopolistic firm. Although we expect our main insights to hold in a competitive setting, it would be fruitful to glean additional insights from strategic competition. Second, the current model assumes that no consumers observe the firm's BBP decision. Research could further investigate the case when the firm's BBP decision is imperfectly observed. For example, Gavazza and Lizzeri (2009) consider the imperfect observation of political commitments. Finally, this research focuses on how firms use consumers' purchase history data to price discriminate. Future research could explore how firms use other types of consumer data to tailor prices and other marketing offerings to consumers. 


\section{References}

Acquisti, A., Brandimarte, L., and Loewenstein, G. (2015). Privacy and human behavior in the age of information. Science, 347(6221), 509-514.

Acquisti, A., and Varian, H. R. (2005). Conditioning prices on purchase history. Marketing Science, 24(3), 367-381.

Amaldoss, W., and He, C. (2018). The charm of behavior-based pricing: effects of product valuation, reference dependence, and switching cost. Working Paper, Duke University.

Ben-Porath, E., Dekel, E., and Lipman, B. L. (2018). Disclosure and Choice. Review of Economic Studies, forthcoming.

Bester, H. (1998). Quality uncertainty mitigates product differentiation. RAND Journal of Economics, 29(4), 828-844.

Brandom, R. (2018). How Europe's new privacy rule is reshaping the internet. The Verge, https: //wWw.theverge.com/2018/3/28/17172548/gdpr-compliance-requirementsprivacy-notice.

Bread, PM-W. (2016). 8 ways retailers are tracking your every move. Money, http://time.com/money/ 4506297 /how-retailers-track-you/.

Choi, C. (2013). How grocery store loyalty programs affect what you buy, how much you spend. Boston Globe, https://www.bostonglobe.com/business/2013/05/16/howgrocery-store-loyalty-programs-affect-what-you-buy-how-much-you-spend/ 8xTOlirUcBDctXrxSQI3TK/story.html.

Clifford, S. (2012). Shopper alert: price may drop for you alone. New York Times, https : / / www . nyt imes . com/ 2012/08/10/business/supermarkets-try-customizing-prices-for-shoppers.html.

Conitzer, V., Taylor, C.R. and Wagman, L. (2012). Hide and seek: Costly consumer privacy in a market with repeat purchases. Marketing Science, 31(2), 277-292.

Coughlan, A. T., and Wernerfelt, B. (1989). On credible delegation by oligopolists: A discussion of distribution channel management. Management Science, 35(2), 226-239.

Essers, L. (2014). Germany orders Google to stop illegal user data processing https : / / www . computerworld. com/article/2689593/government/germany-orders-google-to-stop-illegaluser-data-processing.html.

Esteves, R. B. (2009). A Survey on the economics of behaviour-based price discrimination Working Paper, University of Minho. 
FindLaw (2018). FTC reverses course, recommends comprehensive privacy legislation; senate committee expresses interest. https://corporate.findlaw.com/law-library/ftc-reverses-courserecommends-comprehensive-privacy.html

Fudenberg, D., and Tirole, J. (2000). Customer poaching and brand switching. RAND Journal of Economics, 31(4), $634-657$.

Fudenberg, D., and Villas-Boas, J. M. (2006). Behavior-based price discrimination and customer recognition. Handbook on economics and information systems, 1, 377-436.

Gavazza, A., and Lizzeri, A. (2009). Transparency and economic policy. Review of Economic Studies, 76(3), 10231048.

Goldfarb, A. and Tucker, C. E. (2011). Privacy regulation and online advertising. Management Science, 57(1), 57-71.

Gomis-Porqueras, P., Julien, B., and Wang, C. (2017). Strategic advertising and directed search. International Economic Review, 58(3), 783-806.

Hart, O., and Tirole, J. (1990). Vertical Integration and Market Foreclosure. Brookings Papers on Economic Activity, $205-276$.

In, Y., and Wright, J. (2018). Signaling private choices. Review of Economic Studies, 85(1), 558-580.

Inside Privacy (2015). White House issues report on big data and differential pricing. Covington, https://www.insideprivacy.com/united-states/white-house-issues-report-onbig-data-and-differential-pricing/.

Janrain (2018). Consumer attitudes toward data privacy survey 2018. https://www.janrain.com/ resources/industry-research/consumer-attitudes-toward-data-privacysurvey-2018.

Janssen, M., and Shelegia, S. (2015). Consumer search and double marginalization. American Economic Review, 105(6), 1683-1710.

Jing, B. (2017). Behavior-based pricing, production efficiency, and quality differentiation. Management Science, 63(7), $2365-2376$.

Klein, A. (2017). Hard drive cost per gigabyte. Back Blaze, July 11, https://www.backblaze.com/blog/ hard-drive-cost-per-gigabyte. 
Klein, B., and Leffler, K. B. (1981). The role of market forces in assuring contractual performance. Journal of Political Economy, 89(4), 615-641.

Landes, H. (2012). Individualized coupons aid price discrimination. Forbes, https://www. forbes. com/sites/moneybuilder/2012/08/21/individualized-coupons-aid-pricediscrimination/\#6b433eda45e7.

Lester, B., Postlewaite, A., and Wright, R. (2012). Information, liquidity, asset prices, and monetary policy. Review of Economic Studies, 79(3), 1209-1238.

Li, K. J. (2018). Behavior-based pricing in marketing channels. Marketing Science, 37(2), 310-326.

Li, K. J., Jain, S. (2016). Behavior-based pricing: An analysis of the impact of peer-induced fairness. Management Science, 62(9), 2705-2721.

Li, Y., Rocheteau, G., and Weill, P. O. (2012). Liquidity and the threat of fraudulent assets. Journal of Political Economy, 120(5), 815-846.

McAfee, R. P., and Schwartz, M. (1994). Opportunism in multilateral vertical contracting: Nondiscrimination, exclusivity, and uniformity. American Economic Review, 84(1), 210-230.

McGee, B. (2013). Do travel deals change based on your browsing history? USA Today, https: //www. usatoday.com/story/travel/columnist/mcgee/2013/04/03/do-traveldeals-change-based-on-your-browsing-history/2021993/.

McGuire, T. W., and Staelin, R. (1983). An industry equilibrium analysis of downstream vertical integration. Marketing Science, 2(2), 161-191.

Miller, A. A. (2014). What do we worry about when we worry about price discrimination? The law and ethics of using personal information for pricing. Journal of Technology Law \& Policy, 19, 1-64.

Miller, T. L. (1996). Victoria's Secret lawsuit heard in NY. UPI, https: / /www . upi . com/Archives/1996/ 05/01/Victorias-Secret-lawsuit-heard-in-NY/2694830923200/.

Monga, V. (2014). The big mystery: what's big data really worth? The Wall Street Journal, https: / / www . ws j . com/articles/whats-all-that-data-worth-1413157156.

Morey, T, Forbath, T, and Schoop, A. (2015). Customer data: designing for transparency and trust. Harvard Business Review, May issue, https://hbr.org/2015/05/customer-data-designing-fortransparency-and-trust. 
O'Brien, D. P., and Shaffer, G. (1992). Vertical control with bilateral contracts. RAND Journal of Economics, 23(3), 299-308.

Pazgal, A, Soberman, D. (2008). Behavior-based discrimination: Is it a winning play, and if so, when? Marketing Science, 27(6), 977-994.

Rainie, L. (2016). The state of privacy in post-Snowden America. Pew Research Center, http://www. pewresearch.org/fact-tank/2016/09/21/the-state-of-privacy-in-america/.

Ramasastry, A. (2005). Websites That Charge Different Customers Different Prices: Is Their "Price Customization" Illegal? Should It Be? FindLaw, https://supreme.findlaw.com/legal-commentary/ websites-that-charge-different-customers-diffoerent-prices.html.

Rao, R. C., and Syam, N. (2001). Equilibrium price communication and unadvertised specials by competing supermarkets. Marketing Science, 20(1), 61-81.

Rhee, K. E., and Thomadsen, R. (2017). Behavior-based pricing in vertically differentiated industries. Management Science, 63(8), 2729-2740.

Rhodes, A. (2014). Multiproduct retailing. Review of Economic Studies, 82(1), 360-390.

Rossi, F. and Chintagunta P. K. (2016). Price transparency and retail prices: evidence from fuel price signs in the Italian highway system, Journal of Marketing Research, 53(3), 407-423.

Roy, A., Gilbert, S. M., and Lai, G. (2018). The implications of visibility on the use of strategic inventory in a supply chain. Management Science, forthcoming.

Sadowski, J. (2016). Companies are making money from our personal data - but at what cost? The Guardian, https://www.theguardian.com/technology/2016/aug/31/personal-datacorporate-use-google-amazon.

Savitz, E. (2012). The big cost of big data. Forbes, https: / /www. forbes . com/sites/ciocentral/2012/ $04 / 16 /$ the-big-cost-of-big-data/\#126450b5a3b7.

Shannon, C. E., W. Weaver. (1949). The Mathematical Theory of Communication. University of Illinois Press, Urbana.

Shin, J., and Sudhir, K. (2010). A customer management dilemma: When is it profitable to reward one's own customers? Marketing Science, 29(4), 671-689.

Tucker, C. E. (2014). Social networks, personalized advertising, and privacy controls. Journal of Marketing Research $51(5), 546-562$. 
Villas-Boas, J. M. (1999). Dynamic competition with customer recognition. RAND Journal of Economics, 30(4), 604631.

Villas-Boas, J. M. (2004). Price cycles in markets with customer recognition. RAND Journal of Economics, 35(3), $486-501$.

Weiss, R. M. and A. K. Mehrotra (2001). Online dynamic pricing: efficiency, equity and the future of E-commerce. Virginia Journal of Law and Technology Association, 11, 1-11.

Wells, J. (2017). Study: personalized pricing discounts could be a slippery slope. Food Dive, https: //www. fooddive.com/news/grocery--study-personalized-pricing-discountscould-be-a-slippery-slope/443966/.

Wolinsky, A. (1983). Prices as signals of product quality. Review of Economic Studies, 50(4), 647-658.

Woolley, S. (1998). I got it cheaper than you. Forbes, https://www. forbes.com/forbes/1998/1102/ $6210082 a \cdot h t m l \# 1387 a 014 d 244$.

Zhang, J. (2011). The perils of behavior-based personalization. Marketing Science, 30(1), 170-186. 


\section{Appendix}

\section{A. Technical Details}

Proof of Lemma 1: The case $s=\emptyset$ is straightforward, and we omit the proof. Now consider the case $s=$ BBP. Let $v$ be the indifferent consumer from period 1 . The indifference condition is specified as

$$
v-p_{1}+\left(v-p_{2}^{r}\right)^{+}=v-p_{2}^{n} .
$$

In period 2, the firm faces two segments of consumers: previous consumers (who bought the product) with valuation $v_{i} \geq v$ and new consumers (who did not buy the product) with $v_{i}<v$. Simple analysis shows that the optimal secondperiod prices are $p_{2}^{r}=\max \left\{v, \frac{1}{2}\right\}$ and $p_{2}^{n}=\frac{v}{2}$. Plugging them into Equation 3 yields $v=2 p_{1}$. Optimizing the firm's profit yields $p_{1}=p_{2}^{n}=\frac{3}{10}$ and $p_{2}^{r}=\frac{3}{5}$. In equilibrium, the firm's profit from BBP is $\pi^{\mathrm{BBP}}=\frac{9}{20}-F$, where $F$ is the BBP implementation cost.

Because $\pi^{\mathrm{BBP}}<\pi^{\emptyset}=\frac{1}{2}$ for all $F \geq 0$, we prove the lemma. Q.E.D.

Proof of Proposition 1: Under RI refinement, it suffices to consider the reordered game in which the firm first chooses the first-period price $p_{1}$ and then chooses $s$. We use subgame perfection to pin down consumers' belief about $s$ given price $p_{1}$. In the analysis, we consider first pure-strategy equilibria and then mixed-strategy equilibria.

Case 1: $s=\emptyset$

Given $p_{1}$, suppose that there is a pure strategy equilibrium in which the firm always chooses $s=\emptyset$. In equilibrium, consumers hold the belief $\Lambda\left(p_{1}\right)=0$. Under this belief, in period 1 all consumers with valuations $v_{i} \geq p_{1}$ make an initial purchase, and the firm's first-period profit is guaranteed to be $\pi_{1}=p_{1}\left(1-p_{1}\right)$ regardless of whether it practices BBP. Now consider now how the firm's BBP decision affects its second-period profit.

- If $s=\emptyset$, the firm is not able to price discriminate against the consumers. The firm's optimal second-period price is $p_{2}=\frac{1}{2}$, making a second-period profit of $\pi_{2}^{\emptyset}=\frac{1}{4}$.

- If $s=\mathrm{BBP}$, the firm is able to distinguish between two types of consumers: (1) previous consumers with valuations $v_{i} \in\left[p_{1}, 1\right]$ who made a purchase in period 1 and (2) new consumers with valuations $v_{i} \in\left[0, p_{1}\right)$ who did not buy. The firm charges a price $p_{2}^{r}$ to the previous consumers and a price $p_{2}^{n}$ to the new consumers. Simple calculation shows that the firm's optimal second-period prices are 


$$
p_{2}^{r}= \begin{cases}p_{1} & \text { if } p_{1} \geq \frac{1}{2} \\ \frac{1}{2} & \text { otherwise }\end{cases}
$$

and $p_{2}^{n}=\frac{p_{1}}{2}$. The firm's second-period profit is

$$
\pi_{2}^{\mathrm{BBP}}= \begin{cases}\left(1-p_{1}\right) p_{1}+\frac{p_{1}^{2}}{4} & \text { if } p_{1} \geq \frac{1}{2} \\ \frac{1}{4}+\frac{p_{1}^{2}}{4} & \text { otherwise }\end{cases}
$$

In equilibrium, the firm has no incentive to deviate (i.e., it prefers not to practice BBP) iff $\pi^{\mathrm{BBP}} \leq \pi^{\emptyset}$, which translates to $\pi_{2}^{\mathrm{BBP}}-F \leq \pi_{2}^{\emptyset}$. Solving the inequality, we obtain the existing conditions for the equilibrium: (1) $F \geq \frac{1}{12}$, or (2) $p_{1} \leq \underline{p_{1}}$, or (3) $p_{1} \geq \frac{2+\sqrt{1-12 F}}{3}$, where

$$
\underline{p_{1}}= \begin{cases}2 \sqrt{F} & \text { if } F \leq \frac{1}{16}, \\ \frac{2-\sqrt{1-12 F}}{3} & \text { if } \frac{1}{16} \leq F \leq \frac{1}{12} .\end{cases}
$$

\section{Case 2: $s=$ BBP}

Given $p_{1}$, suppose that there is a pure strategy equilibrium in which the firm always chooses $s=$ BBP. In equilibrium, consumers hold the belief that $\Lambda\left(p_{1}\right)=1$. Given this belief, let $v$ denote the marginal consumer who is indifferent about purchasing at $t=1$. The indifference condition for the marginal consumer is

$$
v-p_{1}+\left(v-p_{2}^{r}\right)^{+}=v-p_{2}^{n}
$$

where the left-hand side is the consumer's surplus if he or she buys in period 1 and the right-hand side is his or her surplus if he or she does not buy in period 1. In equilibrium, $p_{2}^{r}=\max \left\{\frac{1}{2}, v\right\}$ and $p_{2}^{n}=\frac{v}{2}$, we obtain the following condition:

$$
v-p_{1}=\frac{v}{2}
$$

Solving the indifference condition yields $v=2 p_{1}$, and the firm's first-period profit is

$$
\pi_{1}= \begin{cases}\left(1-2 p_{1}\right) p_{1} & \text { if } p_{1} \leq \frac{1}{2} \\ 0 & \text { otherwise }\end{cases}
$$


regardless of whether it practices BBP. Note that when $p_{1}>\frac{1}{2}$, no consumers buy at $t=1$, and thus we say the indifferent consumer is located at $v=1$.

Now consider the firm's second-period profit. Again, consider the following two cases.

- If $s=\emptyset$, the firm cannot price discriminate against the consumers. Its optimal strategy is $p_{2}=\frac{1}{2}$, leading to a second-period profit of $\pi_{2}^{\emptyset}=\frac{1}{4}$.

- If $s=\mathrm{BBP}$, the firm can distinguish between two types of consumers: (1) previous consumers with valuations $v_{i} \in[v, 1]$ and (2) new consumers with valuations $v_{i} \in[0, v)$. The firm optimally charges $p_{2}^{r}$ to previous consumers (when $p_{1}>\frac{1}{2}$, there are no previous consumers) and $p_{2}^{n}$ to new consumers, where

$$
p_{2}^{r}= \begin{cases}2 p_{1} & \text { if } \frac{1}{4} \leq p_{1} \leq \frac{1}{2} \\ \frac{1}{2} & \text { otherwise }\end{cases}
$$

and

$$
p_{2}^{n}= \begin{cases}\frac{1}{2} & \text { if } p_{1} \geq \frac{1}{2} \\ p_{1} & \text { otherwise }\end{cases}
$$

The firm's second-period profit is given by

$$
\pi_{2}^{\mathrm{BBP}}= \begin{cases}\frac{1}{4} & \text { if } p_{1} \geq \frac{1}{2} \\ 2 p_{1}-3 p_{1}^{2} & \text { if } \frac{1}{4} \leq p_{1} \leq \frac{1}{2} \\ \frac{1}{4}+p_{1}^{2} & \text { otherwise. }\end{cases}
$$

In equilibrium, the firm has no incentive to deviate (i.e., it prefers to practice BBP) iff $\pi^{\mathrm{BBP}} \geq \pi^{\emptyset}$, which translates to $\pi_{2}^{\mathrm{BBP}}-F \geq \pi_{2}^{\emptyset}$. Solving the inequality yields the existing conditions for the equilibrium: $F \leq \frac{1}{12}$ and

$$
\begin{cases}\sqrt{F} \leq p_{1} \leq \frac{2+\sqrt{1-12 F}}{6} & \text { if } F \leq \frac{1}{16} \\ \frac{2-\sqrt{1-12 F}}{6} \leq p_{1} \leq \frac{2+\sqrt{1-12 F}}{6} & \text { if } \frac{1}{16} \leq F \leq \frac{1}{12}\end{cases}
$$

\section{Case 3: Mixed-Strategy Equilibria}

Next, consider the case when the firm randomizes its choice between BBP and $\emptyset$. Let $\lambda=\Lambda\left(p_{1}\right)$ be the consumers' beliefs that $\operatorname{Pr}\left[s=\mathrm{BBP} \mid p_{1}\right]$. Let $v$ be the indifferent consumer from period 1 . In period 2 , if $s=\emptyset$, the firm charges all consumers $p_{2}=\frac{1}{2}$. If $s=\mathrm{BBP}$, the firm charges new consumers $p_{2}^{n}=\frac{v}{2}$ and previous consumers $p_{2}^{r}=\max \left\{\frac{1}{2}, v\right\}$. Therefore, the indifference condition is given by 


$$
v-p_{1}+\lambda\left(v-p_{2}^{r}\right)^{+}+(1-\lambda)\left(v-p_{2}\right)^{+}=\lambda\left(v-p_{2}^{n}\right)^{+}+(1-\lambda)\left(v-p_{2}\right)^{+},
$$

which can be simplified as

$$
v-p_{1}=\lambda \cdot \frac{v}{2} .
$$

In a mixed-strategy equilibrium, the firm must be indifferent about practicing BBP or not; that is $\pi^{\mathrm{BBP}}=\pi^{\emptyset}$, or equivalently, $\pi_{2}^{\mathrm{BBP}}-F=\pi_{2}^{\emptyset}$. This leads to

$$
\begin{cases}F=\frac{v^{2}}{4} & \text { if } v \leq \frac{1}{2} \\ F=v-\frac{3 v^{2}}{4}-\frac{1}{4} & \text { otherwise. }\end{cases}
$$

Solving the equilibrium, we have three mixed-strategy equilibria:

(i) $v=2 \sqrt{F}, \lambda=2-\frac{p_{1}}{\sqrt{F}}$, where the equilibrium is sustained if $F \leq \frac{1}{16}$ and $\sqrt{F} \leq p_{1} \leq 2 \sqrt{F}$;

(ii) $v=\frac{2-\sqrt{1-12 F}}{3}, \lambda=\frac{2\left(1+4 F-2 p_{1}-\sqrt{1-12 F} p_{1}\right)}{1+4 F}$, where the equilibrium is sustained if $\frac{1}{16} \leq F \leq \frac{1}{12}$ and $\frac{2-\sqrt{1-12 F}}{6} \leq$ $p_{1} \leq \frac{2-\sqrt{1-12 F}}{3} ;$

(iii) $v=\frac{2+\sqrt{1-12 F}}{3}, \lambda=\frac{2\left(1+4 F-2 p_{1}+\sqrt{1-12 F} p_{1}\right)}{1+4 F}$, where the equilibrium is sustained if $F \leq \frac{1}{12}$ and $\frac{2+\sqrt{1-12 F}}{6} \leq p_{1} \leq$ $\frac{2+\sqrt{1-12 F}}{3}$.

\section{Equilibrium Refinement}

Given this analysis, there may be multiple equilibria for some $p_{1}$. When there are multiple equilibria, we select the equilibrium with the smallest $\Lambda\left(p_{1}\right)$. In other words, we favor the no-BBP equilibrium over the BBP equilibrium. The rationale is that our refinement criterion is least favorable to the BBP equilibrium. If the firm practices BBP under our refinement criterion, it will practice BBP under any other refinement criterion. Therefore, our finding that BBP can be an equilibrium outcome is robust to the refinement criterion.

\section{The Equilibrium}

Given the subgame-perfect equilibrium in the reordered game, the firm chooses $p_{1}$ that will maximize its profit. This leads to the equilibrium strategy summarized in Table 2. Q.E.D.

Proof of Proposition 2. The proposition follows immediately from Table 2. Q.E.D.

Proof of Proposition 3. First, when $F<\frac{7-2 \sqrt{10}}{45}$, the firm practices BBP. In period 1, the indifferent consumer is located 
at $v=2 p_{1}=\frac{3}{5}$, and all consumers with valuation $v_{i} \geq v$ buy the product. In period 2 , all previous consumers purchase the product at $p_{2}^{r}$, and all new consumers with valuation $v_{i} \geq p_{2}^{n}$ buy the product at $p_{2}^{n}$. Consumer surplus is

$$
C S=\int_{v}^{1}\left(x-p_{1}\right) d x+\int_{v}^{1}\left(x-p_{2}^{r}\right) d x+\int_{p_{2}^{n}}^{v}\left(x-p_{2}^{n}\right) d x=\frac{13}{40}
$$

Second, when $F \geq \frac{7-2 \sqrt{10}}{45}$, the firm does not practice BBP. In period 1, all consumers with valuation $v_{i} \geq p_{1}$ buy the product, and in period 2 , all consumers with valuation $v_{i} \geq p_{2}$ buy the product. Consumer surplus is

$$
C S=\int_{p_{1}}^{1}\left(x-p_{1}\right) d x+\int_{p_{2}}^{1}\left(x-p_{2}\right) d x= \begin{cases}\frac{5}{8}-2 \sqrt{F}+2 F & \text { if } \frac{7-2 \sqrt{10}}{45} \leq F \leq \frac{1}{16} \\ \frac{1}{4} & \text { otherwise. }\end{cases}
$$

The proof follows immediately. Q.E.D.

Proof of Proposition 4. First, when $F<\frac{7-2 \sqrt{10}}{45}$, the firm practices BBP. In period 1, the indifferent consumer is located at $v=2 p_{1}=\frac{3}{5}$, and all consumers with valuation $v_{i} \geq v$ buy the product. In period 2 , all previous consumers purchase the product at $p_{2}^{r}$, and all new consumers with valuation $v_{i} \geq p_{2}^{n}$ buy the product at $p_{2}^{n}$. Social welfare is

$$
S W=\int_{v}^{1} x d x+\int_{p_{2}^{n}}^{1} x d x-F=\frac{31}{40}-F
$$

where the last term on the right-hand side is the deadweight loss in implementing BBP.

Second, when $F \geq \frac{7-2 \sqrt{10}}{45}$, the firm does not practice BBP. In period 1, all consumers with valuation $v_{i} \geq p_{1}$ buy the product, and in period 2 , all consumers with valuation $v_{i} \geq p_{2}$ buy the product. Social welfare is

$$
S W=\int_{p_{1}}^{1} x d x+\int_{p_{2}}^{1} x d x= \begin{cases}\frac{7}{8}-2 F & \text { if } \frac{7-2 \sqrt{10}}{45} \leq F \leq \frac{1}{16} \\ \frac{3}{4} & \text { otherwise }\end{cases}
$$

The proof follows immediately. Q.E.D.

Proof of Proposition 5. Under a data transparency regulation, the firm achieves the perfect information benchmark; that is, it does not practice BBP and charges $p_{1}=p_{2}=\frac{1}{2}$. In equilibrium, the firm's profit is $\pi=\frac{1}{4}$ and consumer surplus is

$$
C S=\int_{\frac{1}{2}}^{1}\left(x-\frac{1}{2}\right) d x+\int_{\frac{1}{2}}^{1}\left(x-\frac{1}{2}\right) d x=\frac{1}{4} .
$$

Comparing these results with the equilibrium outcome under imperfect information (see Table 2 and Proposition 3), 
the proposition follows immediately. Q.E.D.

Proof of Proposition 6: As with the base model, we consider the reordered game in which the firm first chooses $p_{1}$ and then chooses $s$.

Case 1: $s=\emptyset$

Given price $p_{1}$, we first consider the pure strategy equilibrium in which the firm always chooses $s=\emptyset$. In equilibrium, consumers believe that $\Lambda\left(p_{1}\right)=0$. Given this belief, the firm's first-period profit is always $\pi_{1}=p_{1}\left(1-p_{1}\right)$ regardless of whether it practices BBP. Now consider the firm's second-period profit:

- If $s=\emptyset$, the firm's optimal second-period price is $p_{2}=\frac{1}{2}$, making a profit of $\pi_{2}^{\emptyset}=\frac{1}{4}$.

- If $s=\mathrm{BBP}$, the firm's optimal second-period prices are

$$
p_{2}^{r}= \begin{cases}p_{1}+\Delta & \text { if } p_{1} \geq \frac{1-\Delta}{2} \\ \frac{1+\Delta}{2} & \text { otherwise }\end{cases}
$$

and $p_{2}^{n}=\frac{p_{1}}{2}$. The firm's second-period profit is

$$
\pi_{2}^{\mathrm{BBP}}= \begin{cases}\left(1-p_{1}\right)\left(p_{1}+\Delta\right)+\frac{p_{1}^{2}}{4} & \text { if } p_{1} \geq \frac{1-\Delta}{2} \\ \frac{(1+\Delta)^{2}}{4}+\frac{p_{1}^{2}}{4} & \text { otherwise. }\end{cases}
$$

In equilibrium, the firm has no incentive to deviate (i.e., it chooses $s=\emptyset$ ) iff $\pi^{\mathrm{BBP}} \leq \pi^{\emptyset}$, which translates to $\pi_{2}^{\mathrm{BBP}}-F \leq$ $\pi_{2}^{\emptyset}$. Solving the inequality, we know that the equilibrium is sustained if (1) $F \geq \frac{(1+2 \Delta)^{2}}{12}$, or (2) $p_{1} \leq \underline{p_{1}}$, or (3) $p_{1} \geq \frac{2(1-\Delta)+\sqrt{(1+2 \Delta)^{2}-12 F}}{3}$, where

$$
\underline{p_{1}}= \begin{cases}\sqrt{4 F-2 \Delta-\Delta^{2}} & \text { if } F \leq \frac{1+6 \Delta+5 \Delta^{2}}{16} \\ \frac{2(1-\Delta)-\sqrt{(1+2 \Delta)^{2}-12 F}}{3} & \text { if } \frac{1+6 \Delta+5 \Delta^{2}}{16} \leq F \leq \frac{(1+2 \Delta)^{2}}{12} .\end{cases}
$$

\section{Case 2: $s=\mathbf{B B P}$}

Given consumers' beliefs, let $v$ be the marginal consumer who is indifferent about purchasing at $t=1$. The indifference condition can be written as

$$
v-p_{1}=v-p_{2}^{n}=\frac{v}{2}
$$

Thus, the indifferent consumer is located at $v=2 p_{1}$, and the firm's first-period profit is $\pi_{1}=\left(1-2 p_{1}\right) p_{1}$ if $p_{1} \leq \frac{1}{2}$ regardless of its true type. Otherwise, if $p_{1}>\frac{1}{2}$, no consumer buys at $t=1$. 
Now consider the firm's second-period profit:

- If $s=\emptyset$, its best strategy is $p_{2}=\frac{1}{2}$, leading to a profit of $\pi_{2}^{\emptyset}=\frac{1}{4}$.

- If $s=\mathrm{BBP}$, the firm optimally charges $p_{2}^{r}$ to previous consumers (when $p_{1}>\frac{1}{2}$, there are no previous consumers) and $p_{2}^{n}$ to new consumers, where

$$
p_{2}^{r}= \begin{cases}2 p_{1}+\Delta & \text { if } \frac{1-\Delta}{4} \leq p_{1} \leq \frac{1}{2} \\ \frac{1+\Delta}{2} & \text { otherwise }\end{cases}
$$

and

$$
p_{2}^{n}= \begin{cases}\frac{1}{2} & \text { if } p_{1} \geq \frac{1}{2} \\ p_{1} & \text { otherwise }\end{cases}
$$

The firm's profit is given by

$$
\pi_{2}^{\mathrm{BBP}}= \begin{cases}\frac{1}{4} & \text { if } p_{1} \geq \frac{1}{2} \\ 2 p_{1}-3 p_{1}^{2}+\Delta-2 \Delta p_{1} & \text { if } \frac{1-\Delta}{4} \leq p_{1} \leq \frac{1}{2} \\ \frac{(1+\Delta)^{2}}{4}+p_{1}^{2} & \text { otherwise }\end{cases}
$$

In equilibrium, the firm has no incentive to deviate (i.e., it chooses $s=\mathrm{BBP}$ ) iff $\pi^{\mathrm{BBP}} \geq \pi^{\emptyset}$, which is translates to $\pi_{2}^{\mathrm{BBP}}-F \geq \pi_{2}^{\emptyset}$. Solving the inequality, we know that the equilibrium is sustained if $F \leq \frac{(1+2 \Delta)^{2}}{12}$ and

$$
\begin{cases}\frac{\sqrt{4 F-2 \Delta-\Delta^{2}}}{2} \leq p_{1} \leq \frac{2(1-\Delta)+\sqrt{(1+2 \Delta)^{2}-12 F}}{6} & \text { if } F \leq \frac{1+6 \Delta+5 \Delta^{2}}{16} \\ \frac{2(1-\Delta)-\sqrt{(1+2 \Delta)^{2}-12 F}}{6} \leq p_{1} \leq \frac{2(1-\Delta)+\sqrt{(1+2 \Delta)^{2}-12 F}}{6} & \text { if } \frac{1+6 \Delta+5 \Delta^{2}}{16} \leq F \leq \frac{(1+2 \Delta)^{2}}{12} .\end{cases}
$$

\section{Case 3: Mixed-Strategy Equilibria}

Next, consider the case in which the firm randomizes its choice between BBP and $\emptyset$. Let $\lambda=\Lambda\left(p_{1}\right)$ be the consumers' beliefs that $\operatorname{Pr}\left[s=\operatorname{BBP} \mid p_{1}\right]$. Let $v$ be the indifferent consumer from period 1. In period 2, if $s=\emptyset$, the firm charges all consumers $p_{2}=\frac{1}{2}$. If $s=\mathrm{BBP}$, the firm charges new consumers $p_{2}^{n}=\frac{v}{2}$ and previous consumers $p_{2}^{r}=\max \left\{\frac{1+\Delta}{2}, v+\right.$ $\Delta\}$. Therefore, the following equation characterize the indifference condition:

$$
v-p_{1}+\lambda\left(v+\Delta-p_{2}^{r}\right)^{+}+(1-\lambda)\left(v-p_{2}\right)^{+}=\lambda\left(v-p_{2}^{n}\right)^{+}+(1-\lambda)\left(v-p_{2}\right)^{+},
$$

which can be simplified to

$$
v-p_{1}=\lambda \cdot \frac{v}{2} .
$$


In a mixed-strategy equilibrium, the firm must be indifferent about practicing BBP or not. This leads to

$$
\begin{cases}F=\frac{1}{4}\left(v^{2}+2 \Delta+\Delta^{2}\right) & \text { if } v \leq \frac{1-\Delta}{2} \\ F=\frac{1}{4}(1-v)(3 v-1+4 \Delta) & \text { otherwise }\end{cases}
$$

Solving the equilibrium, we have three mixed-strategy equilibria:

(i) $v=\sqrt{4 F-2 \Delta-\Delta^{2}}, \lambda=2-\frac{2 p_{1}}{\sqrt{4 F-2 \Delta-\Delta^{2}}}$, where the equilibrium is sustained if $F \leq \frac{1+6 \Delta+5 \Delta^{2}}{16}$ and $\lambda \in[0,1]$;

(ii) $v=\frac{2-2 \Delta-\sqrt{(1+2 \Delta)^{2}-12 F}}{3}, \lambda=\frac{2\left(1+4 F-4 \Delta+2 \Delta p_{1}-2 p_{1}-\sqrt{(1+2 \Delta)^{2}-12 F} p_{1}\right)}{1-4 \Delta+4 F}$, where the equilibrium is sustained if $\frac{1+6 \Delta+5 \Delta^{2}}{16} \leq F \leq \frac{(1+2 \Delta)^{2}}{12}$ and $\lambda \in[0,1]$

(iii) $v=\frac{2-2 \Delta+\sqrt{(1+2 \Delta)^{2}-12 F}}{3}, \lambda=\frac{2\left(1+4 F-4 \Delta+2 \Delta p_{1}-2 p_{1}+\sqrt{(1+2 \Delta)^{2}-12 F} p_{1}\right)}{1-4 \Delta+4 F}$, where the equilibrium is sustained if $F \leq \frac{(1+2 \Delta)^{2}}{12}$ and $\lambda \in[0,1]$.

Following the proof of Proposition 1, when there are multiple equilibria for the subgame, we select the equilibrium with the smallest $\Lambda\left(p_{1}\right)$. In other words, we favor the no-BBP equilibrium over the BBP equilibrium. Given the subgame equilibrium, the firm chooses $p_{1}$ that maximizes its entire profit. Solving the firm's problem yields the equilibrium strategy which is summarized in Table 3. Q.E.D.

\section{Details on Downward Price Distortion}

We consider the case when the firm does not want to practice BBP and examine how the firm commits to a no-BBP equilibrium. The distortionless solution for the firm is to price at $p_{1}=p_{2}=\frac{1}{2}$. In each period, the firm makes a profit of $p_{t}\left(1-p_{t}\right)=\frac{1}{4}$ and its total profit is $\frac{1}{2}$. The question is, given price $p_{1}=\frac{1}{2}$, do consumers really believe that the firm does not practice BBP?

To answer this question, we assume that is an equilibrium in which the firm does not practice BBP and charges the distortionless price $p_{1}=\frac{1}{2}$. Consumers hold equilibrium beliefs that the firm does not practice BBP. Now consider the following deviance: the firm charges $p_{1}=\frac{1}{2}$ but secretly practices BBP. Because consumers do not observe the deviance, their beliefs and the firm's period-1 profit are not affected, and consumers with valuations $v_{i} \in\left[\frac{1}{2}, 1\right]$ purchase the good in period 1 . Under the deviance, the firm optimally charges $p_{2}^{r}=\frac{1}{2}$ and $p_{2}^{n}=\frac{1}{4}$ to previous and new consumers in period 2, respectively. The firm's period-2 profit under deviance is $\frac{5}{16}\left(\frac{1}{2} \times \frac{1}{2}\right.$ from previous consumers and $\frac{1}{4} \times \frac{1}{4}$ from new consumers). In this case, the value of price discrimination is $\frac{5}{16}-\frac{1}{4}=\frac{1}{16}$, where $\frac{1}{4}$ is the firm's period-2 profit if it does not practice BBP. The firm has no incentive to deviate iff $F \geq \frac{1}{16}$. In other words, when $F \geq \frac{1}{16}$, the firm can signal its choice $s=\mathrm{BBP}$ using a distortionless period-1 price $p_{1}=\frac{1}{2}$. 
Given this analysis, when $F<\frac{1}{16}$, the firm cannot credibly commit to a no-BBP equilibrium at the distortionless price $p_{1}=\frac{1}{2}$. To convince consumers that it does not practice BBP, the firm must choose a price $p_{1} \neq \frac{1}{2}$. Assume that there is an equilibrium in which the firm does not practice BBP and charges a price $p_{1}$. Consumers hold the belief that the firm does not practice BBP. Again, consider the following deviance: the firm charges the equilibrium price $p_{1}$ but secretly practices BBP. Because consumers do not observe the deviance, the firm's period-1 profit is not affected, and consumers with valuations $v_{i} \in\left[p_{1}, 1\right]$ purchase the good in period 1 . In period 2, there are two types of consumers: previous consumers with valuations $v_{i} \geq p_{1}$ and new consumers with valuations $v_{i}<p_{1}$. Simple calculation shows that the deviating firm's optimal period-2 prices are $p_{2}^{r}=\max \left\{p_{1}, \frac{1}{2}\right\}$ and $p_{2}^{n}=\frac{p_{1}}{2}$, yielding a total profit of

$$
\pi_{2}^{\mathrm{BBP}}=\max \left\{p_{1}\left(1-p_{1}\right), \frac{1}{4}\right\}+\frac{p_{1}^{2}}{4}
$$

where $\max \left\{p_{1}\left(1-p_{1}\right), \frac{1}{4}\right\}$ is its profit from previous consumers and $\frac{p_{1}^{2}}{4}$ is its profit from new consumers. If the firm does not deviate, its period-2 profit is $\pi_{2}^{\emptyset}=\frac{1}{4}$. Therefore,

$$
\text { The value of price discrimination }=\pi_{2}^{\mathrm{BBP}}-\pi_{2}^{\emptyset}= \begin{cases}\frac{p_{1}^{2}}{4} & \text { if } p_{1}<\frac{1}{2} \\ p_{1}-\frac{3 p_{1}^{2}}{4}-\frac{1}{4} & \text { otherwise. }\end{cases}
$$

To guarantee that the firm has no incentive to deviate, we must impose the following condition

$$
\text { The value of price discrimination }=\pi_{2}^{\mathrm{BBP}}-\pi_{2}^{\emptyset} \leq F \text {. }
$$

Mathematically, when $F \leq \frac{1}{16}$, the no-deviating condition translates to

$$
p_{1} \leq \underline{p_{1}}=2 \sqrt{F} \text { or } p_{1} \geq \overline{p_{1}}=\frac{2+\sqrt{1-12 F}}{3} .
$$

In other words, to convince consumers that it does not practice BBP, the firm either distorts its price downward to $p_{1} \leq \underline{p_{1}}$ or distorts its price upward to $p_{1} \geq \overline{p_{1}}$. In either case, the firm successfully signals to consumers that it does not practice BBP. Its profit is $\pi=p_{1}\left(1-p_{1}\right)+\frac{1}{4}$. Therefore, when the firm wants to signal its no-BBP choice, its problem is

$$
\begin{aligned}
& \max _{p_{1}} p_{1}\left(1-p_{1}\right)+\frac{1}{4}, \\
& \text { s.t. } p_{1} \leq \underline{p_{1}} \text { or } p_{1} \geq \overline{p_{1}} .
\end{aligned}
$$


Simple calculation shows that the firm chooses $p_{1}=p_{1}$; that is, it underprices in period 1 .

Proof of Proposition 7. The proof follows directly from Figure 7 and the text. Q.E.D. 